\title{
Causes of impaired oral vaccine efficacy in developing countries
}

\author{
Edward PK Parker*,1, Sasirekha Ramani², Benjamin A Lopman ${ }^{3}$, James A Church ${ }^{4}$, Miren \\ Iturriza-Gómara ${ }^{5}$, Andrew J Prendergast ${ }^{4} \&$ Nicholas C Grassly ${ }^{1}$ \\ ${ }^{1}$ Department of Infectious Disease Epidemiology, St Mary's Campus, Imperial College London, London, W2 1PG, UK \\ ${ }^{2}$ Baylor College of Medicine, Houston, TX 77060, USA \\ ${ }^{3}$ Department of Epidemiology, Rollins School of Public Health, Emory University, Atlanta, GA 30322, USA \\ ${ }^{4}$ Centre for Paediatrics, Blizard Institute, Queen Mary University of London, London, E1 2AT, UK \\ ${ }^{5}$ Centre for Global Vaccine Research, Institute of Infection \& Global Health, University of Liverpool, Liverpool, L69 7BE, UK \\ * Author for correspondence: edward.parker@imperial.ac.uk
}

Oral vaccines are less immunogenic when given to infants in low-income compared with high-income countries, limiting their potential public health impact. Here, we review factors that might contribute to this phenomenon, including transplacental antibodies, breastfeeding, histo blood group antigens, enteric pathogens, malnutrition, microbiota dysbiosis and environmental enteropathy. We highlight several clear risk factors for vaccine failure, such as the inhibitory effect of enteroviruses on oral poliovirus vaccine. We also highlight the ambiguous and at times contradictory nature of the available evidence, which undoubtedly reflects the complex and interconnected nature of the factors involved. Mechanisms responsible for diminished immunogenicity may be specific to each oral vaccine. Interventions aiming to improve vaccine performance may need to reflect the diversity of these mechanisms.

First draft submitted: 29 June 2017; Accepted for publication: 13 September 2017; Published online: 8 December 2017

Keywords: cholera $\bullet$ enteropathy $\bullet$ histo blood group antigens $\bullet$ immunogenicity $\bullet$ malnutrition $\bullet$ microbiota $\bullet$ oral vaccines $\bullet$ poliovirus $\bullet$ rotavirus

Enteric pathogens are a substantial threat to public health. This threat takes many forms, from the toxin-producing bacteria (e.g., Vibrio cholerae) and flagellated protozoa (e.g., Giardia lamblia) that colonize the mucosal surface of the small intestine to the enteroviruses that are capable of spreading via the bloodstream to the CNS, causing acute flaccid paralysis (e.g., poliovirus). Each year, enteric pathogens cause hundreds of millions of cases of diarrhea and approximately 800,000 deaths, the vast majority of which occur among children in low-income countries [1]. The most common causes of childhood diarrheal morbidity include rotavirus, Cryptosporidium, enterotoxigenic Escherichia coli and Shigella [2].

Vaccines against enteric pathogens are important tools for mitigating this disease burden. Oral vaccines offer several distinct benefits compared with parenteral vaccines. They can be produced in large quantities at relatively low cost, are easy to administer and have the capacity to induce local immunity in the intestinal mucosa, thereby protecting vaccinated individuals against subsequent infection and - by blocking onward transmission - enhancing herd immunity [3,4]. Currently licensed oral vaccines include live-attenuated poliovirus vaccines containing one, two or three serotypes, live-attenuated rotavirus vaccines (Rotarix ${ }^{\circledR}$, RotaTeq ${ }^{\circledR}$, Lanzhou lamb rotavirus vaccine [China only] and Rotavac ${ }^{\circledR}$ [India only]), live-attenuated cholera vaccine (CVD 103-HgR or Vaxchora ${ }^{\mathrm{TM}}$ ), inactivated cholera vaccines (Dukoral ${ }^{\circledR}$ and Shanchol ${ }^{\circledR}$ ) and live-attenuated typhoid vaccine (Ty21a). Other oral vaccines are in development, including those against Shigella, enterotoxigenic E. coli, Campylobacter and Clostridium difficile, as well as several novel rotavirus vaccine candidates (including the human neonatal vaccine RV3-BB [5] and an oral bovine pentavalent vaccine [G]).

Yet oral vaccines have an Achilles' heel - their immunogenicity and efficacy is impaired in low-income countries that experience the greatest burden of enteric disease (Box 1). For example, Rotarix has a 1-year protective efficacy against severe rotavirus-associated gastroenteritis of $>95 \%$ in European infants [7], but less than $50 \%$ in Malawi [8]. Similar deficits in immunogenicity and/or efficacy have been documented for live-attenuated oral cholera 


\section{Box 1. Measures of oral vaccine response.}

- Immunogenicity: ability to induce an immune response. Typical measures in vaccine trials include seroconversion (see below) and post-vaccination antibody concentration (often reported as antibody titers)

- Seroconversion: the appearance of pathogen-specific serum antibodies in a previously seronegative individual, or a significant rise in antibody concentration between pre- and post-vaccination samples

- Shedding (post-vaccination): the detection of vaccine components in stool samples collected after immunization. Post-vaccination shedding indicates replication of live-attenuated vaccines, and is generally correlated with immunogenicity

- Vaccine efficacy: the percentage reduction in disease in vaccinated compared with unvaccinated individuals under optimal conditions (e.g., clinical trials)

- Vaccine effectiveness: the ability of a vaccine to prevent outcomes of interest during routine use

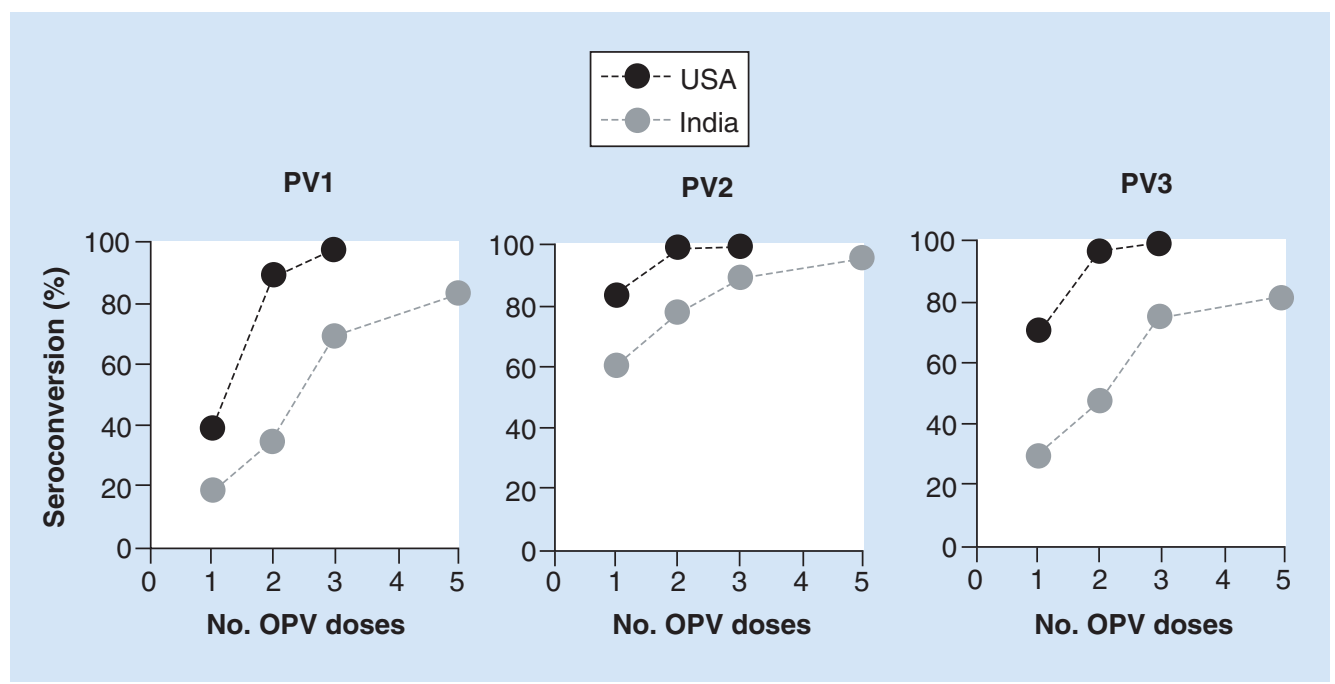

Figure 1. Impaired immunogenicity of oral poliovirus vaccine in India. Seroconversion rates for India are obtained from a report by John [194], which combines results from several trials of trivalent OPV performed in Vellore between 1969 and 1976. Immunogenicity data from the USA are obtained from a study by McBean et al. [195] in which three doses of trivalent OPV were administered to infants in Maryland at 2, 4 and 18 months of age. Seroprevalence estimates at 18 and 20 months of age are interpreted here as seroconversion.

OPV: Oral poliovirus vaccine; PV1: Type 1 poliovirus; PV2: Type 2 poliovirus; PV3: Type 3 poliovirus.

vaccines [9-11] and oral poliovirus vaccine (OPV) (Figure 1) [12]. Limited efficacy of OPV has contributed to the persistence of poliovirus transmission in several countries, delaying global eradication. Ty21a offers moderate efficacy against typhoid fever (reported at $48 \%$ over 3 years in a recent systematic review [13]), although there is no evidence to suggest that this is lower than protection offered to travelers from high-income, non-endemic countries [14,15]. One live-attenuated Shigella vaccine candidate was reactogenic and immunogenic when administered to North-American adults; however, when the same vaccine was tested in Bangladesh, it elicited no adverse reactions and failed to induce a serological response in any recipient $[16,17]$. Poor immunogenicity has also been observed for an oral-killed cholera vaccine among children in Nicaragua compared with Sweden [18]. Thus, poor vaccine immunogenicity and effectiveness have been observed for both killed- and live-oral vaccines targeting bacterial and viral pathogens. The same does not appear to be true of parenterally administered vaccines $[19,20]$.

In addition to geographic variation, oral vaccine immunogenicity can vary by season and age at administration. OPV is less immunogenic when given during warm, humid months [21,22], while Rotarix was shown to have lower immunogenicity during the cool, dry season in Zambia [23]. Oral poliovirus and rotavirus vaccines may be less immunogenic when administered in early infancy (e.g., before 6 weeks of age) compared with later infancy, although the size of this effect is small [24-27] and may be reversed at older ages [28]. The immunogenicity of live-attenuated oral cholera and typhoid vaccines given to children does not appear to be strongly related to age, although it can be affected by pre-existing immunity from natural exposure to these pathogens [29,30]. By contrast, several studies of 


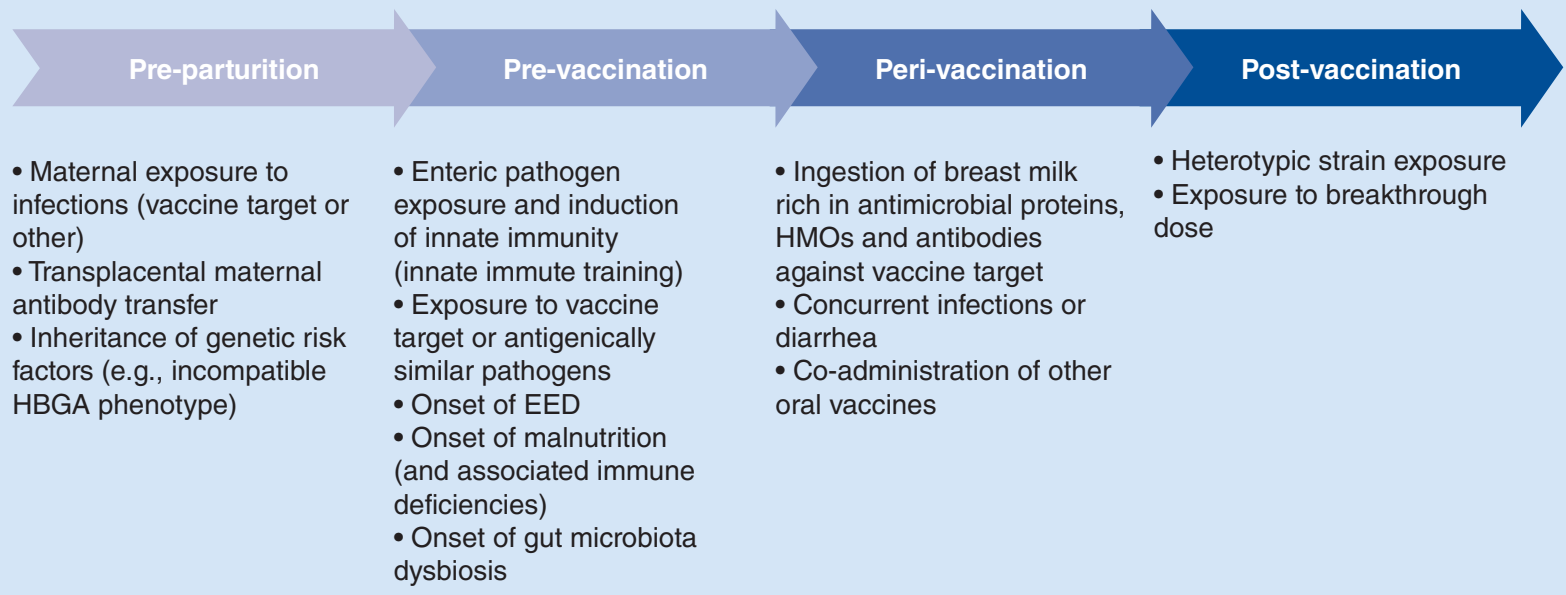

Figure 2. Oral vaccine failure: a timeline of contributing factors.

EED: Environmental enteric dysfunction; HBGA: Histo blood group antigen; HMO: Human milk oligosaccharide.

inactivated oral cholera vaccines have found lower immunogenicity and efficacy among young children $(<5$ years of age) compared with older children [31-34].

In each of these examples, deficits in oral vaccine performance have been observed within the context of trials in which the potency and cold-chain requirements of the administered vaccines were carefully maintained. Logistical failures therefore cannot fully account for poorer performance in the field, although in practice they may exacerbate the issue. What, then, explains the discrepancies in oral vaccine outcomes between high-income and low-income settings? In this review, we consider the biological mechanisms that might account for the geographic variation in oral vaccine performance. These mechanisms are varied, interconnected and play out across a timescale that begins before birth and ends well after immunization (Figures 2 \& 3). Moreover, while the overall trend of impaired performance in developing countries appears to be common to almost all oral vaccines, the mechanisms responsible for this phenomenon may vary between vaccines. Where sufficient evidence is available, we will distinguish between risk factors for vaccine failure that are shared across oral vaccines and those that are specific to individual vaccines. We will also comment on whether these risk factors are consistent with the observed geographic and seasonal trends in vaccine immunogenicity.

\section{Maternal risk factors Transplacental antibodies}

Newborn infants passively acquire serum antibodies from their mothers via the placenta at titers comparable to those in maternal serum [35,36]. These antibodies are predominantly of class IgG (IgA does not cross the placenta [37]) and decay with a half-life of approximately 28 days [38]. Maternally derived antibodies have been shown to interfere with both oral and parenteral vaccines [21,39], and are in this respect distinct from several of the mechanisms considered below. Precise mechanisms of interference remain uncertain, but may involve the masking of vaccine-derived antigens from B- and T-cell receptors [40].

An impaired immune response in infants with elevated titers of passively acquired antibodies has consistently been demonstrated in field trials of OPV [21,41-43], with the greatest inhibitory effect typically observed for serotype 3 [41,43]. Among infants in Brazil who received trivalent OPV at 0, 6, 10 and 14 weeks of age, type 3 seroconversion was observed in $70 \%$ of individuals who had a baseline homotypic antibody titer of less than 1:64, but only $29 \%$ of those with a baseline titer of at least 1:256 [21]. Diminished shedding of vaccine polioviruses after immunization (which correlates strongly with immunogenicity) has been observed among nonbreastfed newborn infants with elevated titers of passively acquired antibodies. This suggests that the inhibitory effect of maternal antibodies on OPV immunogenicity reflects in part a reduction in vaccine virus replication [44,45], possibly mediated by the passive transfer of maternal IgG across the intestinal epithelium (termed transudation) [40]. Passively acquired serum antibodies have also been linked with a reduction in the immunogenicity of oral rotavirus vaccines, including 


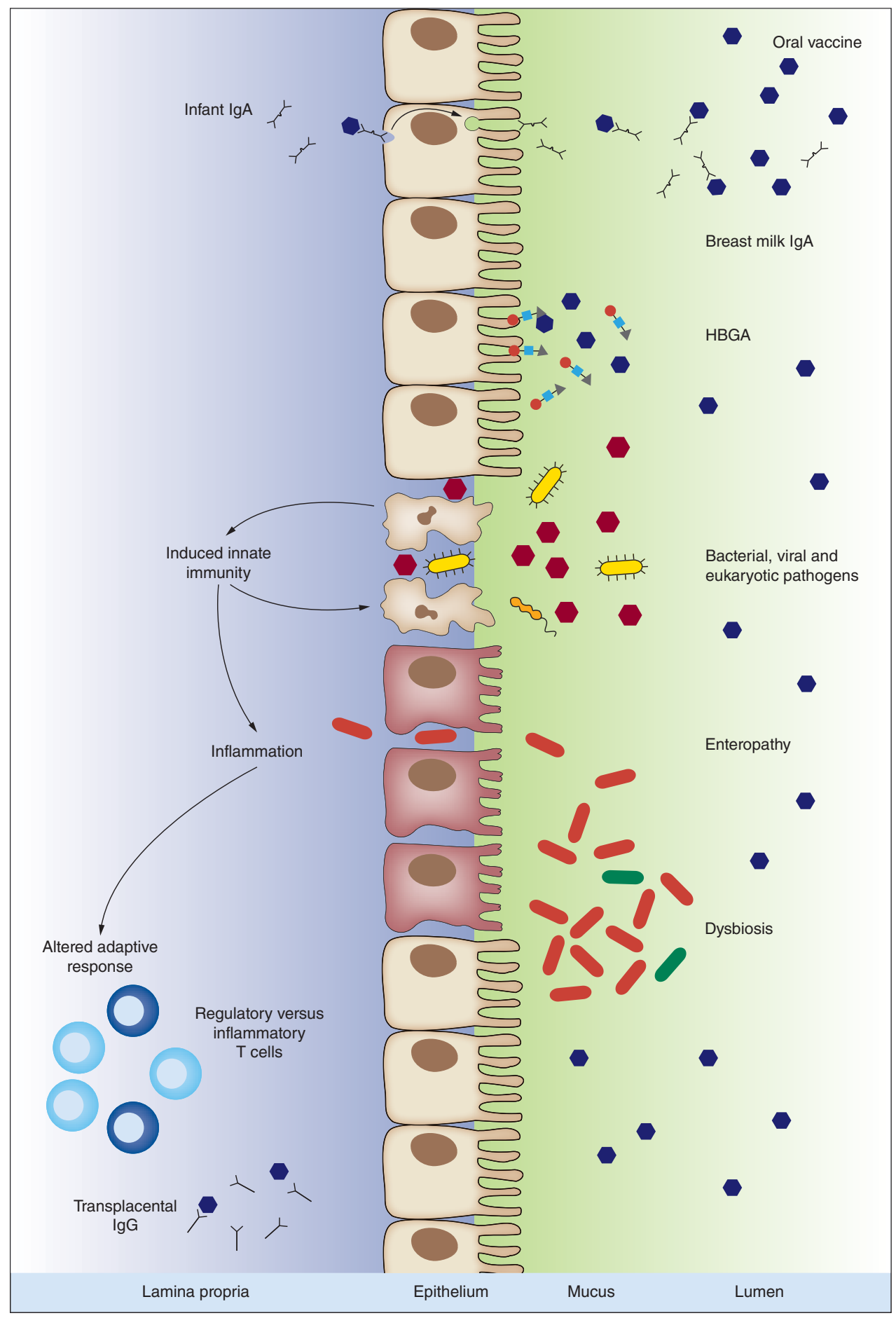

Figure 3. Potential mechanisms underlying variation in oral vaccine efficacy. Upon arrival at the gastrointestinal epithelium, multiple factors may impact the ability of an oral vaccine to replicate and/or cause a protective immune response. Breast milk IgA may neutralize the vaccine, as may infant IgA induced by prior exposure to the infection being targeted. HBGAs act as binding sites for many enteric infections. Their precise structure as well as their presence in mucosal secretions are genetically determined and vary among individuals. The presence of enteric pathogens at the time of immunization may activate innate immune pathways that inhibit the immunogenicity of oral vaccines. Repeated pathogen exposure may also give rise to enteropathy - a subclinical condition associated with increased gut permeability and the induction of a pro-inflammatory state that may inhibit oral vaccine

immunogenicity. The bacterial microbiota is crucial both to the development of the intestinal immune system and the replication of enteric viruses. Perturbations of the microbiota (or dysbiosis) may therefore have an inhibitory effect on oral vaccines. Pathogen exposure, enteropathy and microbiota dysbiosis may also alter the adaptive response to oral vaccines; for example, by inducing regulatory $T$ cells that promote a state of mucosal tolerance. Finally, transplacental IgG in infant serum has been shown to interfere with both oral and parenteral vaccines. HBGA: Histo blood group antigen. 
Rotarix [36], RotaTeq [46] and Rotavac [47]. An increase in seroconversion rates by up to $25 \%$ has been observed following the administration of Rotarix at 10 and 14 weeks of age as opposed to the standard schedule of 6 and 10 weeks (when maternal antibodies will have had less time to decay) [48]. However, a recent study of Rotavac in north India concluded that maternal antibodies explained less than $10 \%$ of variation in post-vaccination antibody levels [49]. Oral cholera and typhoid vaccines are not licensed in infants and studies demonstrating inhibition by transplacental antibodies are therefore lacking.

The degree to which trends in maternal antibodies contribute to the geographic, age-related and seasonal patterns of OPV and rotavirus vaccine performance is less certain. Maternal exposure to natural infection, and consequent boosting of serum antibody titers, will be greatest in places and at times of year that transmission is most efficient, enhancing the potential influence of passively acquired antibodies in young infants. These trends generally appear to correlate with observed patterns of OPV and rotavirus vaccine immunogenicity, although cross-sectional surveys of poliovirus- and rotavirus-specific maternal antibody titers in different sites using standardized methods are currently lacking [50,51]. It is also worth noting that maternal infection with malaria or HIV is associated with a reduction in the transfer of antibodies across the placenta [52]. As such, the effect of maternal antibodies on vaccine immunogenicity may be diminished in populations with a high burden of these infections.

\section{Breastfeeding}

Breast milk has the capacity to directly inhibit replication of vaccine strains in the gut owing to the presence of neutralizing antibodies (predominantly of class IgA), antimicrobial proteins such as lactadherin and lactoferrin, and human milk oligosaccharides that bind enteric viruses, potentially blocking cell entry [53,54]. This may, in turn, contribute to geographic and seasonal variation in oral vaccine performance. Rotavirus-specific $\operatorname{IgA}$ and neutralizing antibody titers tend to be significantly higher in breast milk obtained from mothers in low-income countries (e.g., India and Bangladesh) compared with mothers from high-income countries (e.g., the USA and Sweden) and in the rotavirus high season compared with the low season $[23,55,56]$. Similarly, higher levels of lactoferrin and lactadherin have been observed in breast milk obtained from Indian and South-African women compared with North-American women [57], although these innate immune factors did not correlate with RotaTeq immunogenicity in a recent study in Nicaragua [58]. In the case of poliovirus, significantly higher IgA titers were documented in breast milk samples from unvaccinated women from Pakistan compared with vaccinated women from Japan or Sweden in the early 1990s [59], and it is likely that similar discrepancies between endemic and nonendemic settings persist today. Antibodies against cholera toxin and lipopolysaccharide are also common among mothers in low-income countries [60].

Findings regarding the overall impact of breastfeeding on oral vaccine performance are notable for their lack of consistency. The effects of breastfeeding are confounded with those of transplacental antibodies owing to the close correlation between antibody titers in maternal breast milk and serum [45]. Nonetheless, several studies have documented a reduction in the shedding of vaccine polioviruses in breastfed versus non-breastfed neonates immunized shortly after birth [44,61], and this discrepancy appears to persist across a range of maternal serum antibody titers [45]. Later in infancy, the picture is more ambiguous - while an increase in the duration of breastfeeding was associated with a lower seroconversion rate (significant for serotype 3) following four doses of trivalent OPV among infants in Brazil, breastfeeding status had no effect on seroconversion rates during studies in Uganda [62] and India [63]. To confuse matters further, several studies have documented an improvement in OPV immunogenicity among breastfed infants [43,64,65].

Studies of oral rotavirus vaccines have similarly failed to establish a clear inhibitory or beneficial effect of breastfeeding on vaccine performance. While several trials have observed a reduction in immunogenicity among breastfed infants [66,67], the effect has typically been modest. Recent trials of Rotarix in South Africa, India and Pakistan did not document a significant improvement in seroconversion rate in conjunction with the temporary withholding of breastfeeding immediately before and after vaccination [49,68,69]. Indeed, in the latter study Rotarix immunogenicity was significantly higher among infants who were breastfed at the time of immunization [69]. In the case of inactivated oral cholera vaccine (Dukoral), withholding breastfeeding for $3 \mathrm{~h}$ prior to immunization was associated with a modest increase in immunogenicity (based on vibriocidal antibody titers), although this was only apparent in a subgroup analysis of older children (10-18 months of age) and was not seen for antibodies against cholera toxin [70].

It is possible that the conflicting findings of these studies reflect contradictory influences of breastfeeding on vaccine immunogenicity. On the one hand, IgA and innate immune factors may inhibit the replication of live- 
attenuated oral vaccines - an effect that is likely to be particularly potent in newborns given the elevated titers of antibodies in colostrum. However, breastfeeding may also prevent enteric infections [71], promote the maturation of the infant immune system [72] and buffer vaccine viruses from gastric acid [67], which together may alleviate or indeed reverse the inhibitory effects of breast milk IgA.

\section{Genetic risk factors}

Although unable to account for seasonal fluctuations in oral vaccine response, a role for genetic variation in shaping the immune response to oral vaccines is supported by a study of 207 twin pairs in the Gambia who received multiple doses of OPV [73]. By comparing within-pair correlations in antibody titers between monozygotic and dizygotic twins, approximately $60 \%$ of the variation in OPV response was attributed to heritable factors.

\section{Histo blood group antigens}

Among the potential genetic sources of variation in oral vaccine outcome, histo blood group antigens (HBGAs) are important candidates. HBGAs are ABH and Lewis glycans present on the surface of epithelial cells and in mucosal secretions. HBGA synthesis occurs via the sequential addition of monosaccharides to precursor disaccharides through the expression of genetically encoded glycosyltransferases such as FUT2 (secretor gene) and FUT3 (Lewis gene). Individuals with functional FUT2 are referred to as secretor-positive because HBGAs can be found in mucosal secretions; those with functional FUT3 are referred to as Lewis-positive. The fucosyltransferases are nonfunctional in individuals with mutations in FUT2 and FUT3, and such individuals are referred to as secretor-negative (or nonsecretors) and Lewis-negative, respectively.

A number of enteric pathogens and pathogen-derived toxins use HBGAs as attachment factors. These interactions, in turn, may give rise to marked associations between HBGA phenotype and enteric pathogen susceptibility [74]. For individual pathogens, HBGA interactions are often strain/genotype-specific. For example, secretors are significantly more susceptible than nonsecretors to norovirus genotype GII.4, but the same is not true of other norovirus genotypes such as GII.3 [75]. Rotaviruses are classified into G and P types based on the composition of the outer capsid proteins VP7 and VP4, respectively. Binding to HBGA occurs through the VP8* domain of protein VP4 [76,77]. To date, 47 VP4 (P) genotypes have been identified, of which P[4], P[6] and P[8] are most common. A recent systematic review based on studies in France, Vietnam, the USA and Burkina Faso documented a 27-fold increase in susceptibility to $P[8]$ rotavirus in secretors versus nonsecretors, but showed no association between secretor status and susceptibility to $\mathrm{P}[4]$ or $\mathrm{P}[6]$ genotypes [75]. In Burkina Faso, no Lewis-negative secretors (expressing H type 1 antigen) were infected with P [8] strains, despite making up 25\% of the study population [78], suggesting that the infectivity of $\mathrm{P}[8]$ strains may be dependent on both secretor and Lewis status. However, population-specific differences may exist; for example, $\mathrm{P}[8]$ infections were detected in both secretors and nonsecretors during a study in Tunisia [79].

In addition to being among the globally dominant rotavirus genotypes, $\mathrm{P}[8]$ strains are a component of Rotarix and RotaTeq. It is therefore plausible that genotype-specific HBGA binding patterns may contribute to geographic differences in vaccine efficacy. While nonsecretors make up just $20 \%$ of Caucasians, this phenotype may reach a prevalence of $30-50 \%$ in parts of Bangladesh, India and Pakistan [80-82], where the immunogenicity and efficacy of oral rotavirus vaccines is poor. Similarly, the Lewis-negative phenotype is significantly more common in parts of Africa (reaching $>30 \%$ in some populations) than in Caucasians (4-6\%) [83]. Thus, an impaired replicative capacity of $\mathrm{P}[8]$ strains combined with the high prevalence of $\mathrm{P}[6]$ genotypes in Lewis-negative individuals, as reported in Burkina Faso [78], would be consistent with observed discrepancies in rotavirus vaccine efficacy.

A key challenge for the coming years will be to determine the extent to which host genetic determinants of rotavirus diarrhea susceptibility apply to attenuated vaccine strains. Notably, during a recent study in Pakistan, Rotarix immunogenicity was associated with secretor status and $\mathrm{ABO}$ blood group - seroconversion was seen in $19 \%$ of nonsecretors, $30 \%$ of secretors with non-O blood groups and $51 \%$ of secretors with blood group O [84]. How this poorer immunogenicity impacts clinical protection is not yet clear and may be complex. For example, while nonsecretors may be less likely to respond to vaccination, they will also be less susceptible to natural infection with certain genotypes.

The effect of HBGAs on OPV immunogenicity has not been studied, although blood group O has been linked with an increased occurrence of paralytic poliomyelitis [85]. HBGA phenotype also appears to influence susceptibility to bacterial enteropathogens [86,87], including $V$. cholerae [88,89]. Nonsecretors are more likely to suffer from severe cholera than secretors [90]. Somewhat paradoxically, individuals with blood group $\mathrm{O}$ are less likely to be 
colonized by $V$. cholerae [89], but are more likely, upon colonization, to develop severe symptoms [88,89]. The extent to which HBGA phenotype influences cholera vaccine response remains uncertain. Several studies have documented increased immunogenicity or protective efficacy following administration of CVD $103-\mathrm{HgR}$ to individuals with O versus non-O blood groups [11,91-93], though a recent study in North-American adults failed to replicate these findings [94]. Meanwhile, trials of oral-killed whole-cell vaccines have yielded conflicting results when comparing immunogenicity or efficacy according to $\mathrm{ABO}$ blood type, including observations of either improved or impaired response in individuals with blood group $\mathrm{O}$ (vs non-O) [32,95,96], or no difference according to blood group [97,98]. It is worth noting that regions in which oral cholera vaccine candidates have underperformed (e.g., Thailand and Indonesia) do not differ markedly in blood group $\mathrm{O}$ frequency from those in which a robust vaccine response is seen (e.g., North America) [11,99]. Nonetheless, HBGA phenotype (including Lewis and secretor status) should continue to be a consideration during cholera vaccine trials.

Another relevant genetic factor for future consideration is maternal secretor status. This significantly impacts the quantity and quality of oligosaccharides found in breast milk [100], potentially modifying any direct or indirect effects of breastfeeding on oral vaccine efficacy. Ultimately, the HBGA status of a mother-infant pair may play a role in shaping infant microbiota composition [101,102], mucosal immune development and pathogen receptor expression (in breast milk, mucus and on intestinal epithelial cells), thereby influencing both pathogen susceptibility and oral vaccine outcomes. However, further work is required to disentangle these pathways.

\section{Other genetic associations}

Genetic risk factors for oral vaccine failure may extend beyond HBGAs. Candidate gene and genome-wide association studies have helped to uncover genetic variants that influence the performance of vaccines targeting measles, rubella and hepatitis B, among others [103,104]. Variants within the HLA locus (encoding the major histocompatibility complex proteins involved in antigen presentation) have typically been among the top associations identified. A recent genome-wide association study among infants in Bangladesh identified several single-nucleotide polymorphisms that may contribute to variation in OPV response, including those associated with histone modification [105]. However, there is no reason to suspect that geographic variation in oral vaccine response is correlated with the distribution of these genetic polymorphisms. Analogous studies are presently lacking for oral vaccines other than OPV.

\section{Malnutrition \& micronutrient deficiencies}

Malnutrition is common in the world's poorest countries, and may contribute to more than half of deaths among children under 5 years of age [106]. It appears in various forms, including impaired growth (e.g., stunting) and deficiencies in specific micronutrients (e.g., zinc, iron and vitamin A). Several abnormalities in immune function have been linked with malnutrition, including deficits in secretory IgA, complement production, gut barrier function and T-cell memory maintenance, among others [107]. In spite of these immunological deficits, a consistent link between malnutrition and oral vaccine performance has not been found $[108,109]$. A recent study among infants in Bangladesh documented significantly lower serotype 3 poliovirus antibody titers in conjunction with underweight (weight-for-age Z score $\leq 2$ ) after at least three doses of OPV [65]. However, other studies in India, Nigeria and Pakistan have not observed an association between malnutrition and OPV immunogenicity [110-112]. Similarly, supplementation with vitamin A did not significantly impact OPV seroconversion rates during trials in Bangladesh, Indonesia and Ghana [113-115], while the receipt of zinc supplements (which are known to have a significant therapeutic effect during the treatment of acute gastroenteritis [116]) had no effect on OPV seroconversion during a recent placebo-controlled trial in Pakistan [117].

Data regarding the potential impact of malnutrition on oral vaccines other than OPV are limited [108]. During a trial of CVD 103-HgR in Bangladesh, supplementation with zinc (but not vitamin A) significantly boosted vibriocidal antibody response [118]. Low levels of serum zinc have also been associated with rotavirus risk in Bangladesh [119], though supplementation with zinc did not improve Rotarix immunogenicity during a study in India [120]. Overall, while it remains plausible that malnutrition and micronutrient deficiencies may contribute to the impaired performance of oral vaccines in low-income countries, particularly given their geographic and seasonal patterns of occurrence, we currently lack robust data to support this notion [121]. It is also worth noting that enteric infections and environmental enteropathy are strongly associated with malnutrition [122,123], and may in turn be worsened by its onset. These factors may have a greater impact on oral vaccine performance than malnutrition itself, although teasing apart such effects is likely to prove challenging (see below). 


\section{Environmental exposures}

\section{Enteric infections}

Enteric infections have long been recognized as a major cause of morbidity and mortality among young infants, and this burden is greatest in the developing countries where oral vaccines are least immunogenic $[2,124]$. Enteric infections present at the time of vaccination or in the period leading up to vaccination might impede oral vaccines in several ways. Interference with live-attenuated viral vaccines by viral pathogens may arise via competition for cell entry or receptor binding, or (after entry) for cellular factors required during transcription, replication and assembly - a notion supported by the interference that occurs among the three vaccine poliovirus serotypes when co-administered [12]. Interference might also arise via the induction of nonspecific innate immunity. In particular, type I, II and III interferons induced by viral or bacterial pathogens may inhibit vaccine virus replication and immunogenicity through a number of mechanisms including direct antiviral activity, innate immune cell activation and regulation of adaptive immune responses $[125,126]$. Other immunomodulatory effects may be pertinent, such as the suppression of Th1 cytokine production by intestinal helminths $[127,128]$, the promotion of mucosal tolerance via the induction of regulatory $\mathrm{T}$ cells or the functional reprogramming of innate immune cells that protects against subsequent colonization (trained immunity) [129].

The inhibitory effect of non-polio enteroviruses (NPEVs) on OPV is perhaps the most robust association to be demonstrated between a group of enteric pathogens and an oral vaccine. NPEVs show both geographic and seasonal patterns of incidence that coincide with impaired immunogenicity of OPV [22]. In a systematic review of OPV trials dating back to 1959, the presence of NPEVs at the time of vaccination (detected in stool samples in the absence of symptoms) was consistently associated with a reduction in the odds of seroconversion per dose of OPV, though it remains unclear whether this inhibitory effect varies among enterovirus species [130]. The association between the presence of NPEVs and OPV immunogenicity has since been confirmed by studies in south India [28] and Bangladesh [131] that used sensitive PCR-based methods for the detection of multiple enteric pathogens, including enteroviruses, at the time of OPV administration. In the latter study, enterovirus quantity at 10 weeks of age was also negatively correlated with the immunogenicity and efficacy of Rotarix (administered at 10 and 17 weeks) an effect that was not observed for any other viral, bacterial or eukaryotic pathogen, or for Sabin polioviruses [131]. Thus, the negative repercussions of enterovirus exposure for oral vaccines may extend beyond OPV.

Given that OPV and oral rotavirus vaccines are regularly co-administered as part of routine immunization programs, the potential interference between these attenuated viruses has garnered considerable interest. Rotavirus replication in vitro is impaired by the presence of an enterovirus, but the converse is not true [132]. Consistent with this, vaccine co-administration does not appear to inhibit the immunogenicity of OPV [133]. The situation for rotavirus vaccines may be more complex - while the first dose of either Rotarix or RotaTeq has generally proven to be less immunogenic when administered with OPV than without, after a full course antibody titers are similar in these groups [134]. Nonetheless, among infants in Bangladesh who received Rotarix at 6 and 10 weeks of age, concomitant OPV administration during at least one of these doses was associated with a reduction in rotavirus seroconversion rate (47\%) compared with staggered vaccine administration ( $\geq 1$ day apart) at both doses (63\%) [135]. Thus, it is possible that the continued use of OPV in developing countries (as opposed to the IPV-only schedules generally adopted in high-income countries) contributes to the geographic discrepancies observed in rotavirus vaccine performance.

Aside from the clear inhibitory potential of enteroviruses (either NPEVs or OPV), the relationship between other enteric pathogens and oral vaccine outcome remains equivocal. Concurrent diarrhea has consistently been linked with a reduction in the immunogenicity of OPV $[21,130,136]$. Several studies have also highlighted the potential inhibitory effect of bacterial or eukaryotic pathogens on OPV, often in the absence of gastrointestinal symptoms $[131,137,138]$. However, a 3-day course of azithromycin (a broad-spectrum macrolide antibiotic) did not alter the immunogenicity of a subsequent dose of type 3 monovalent OPV among 6-11 month-old infants in India despite reducing the prevalence of bacterial pathogens (including Campylobacter, Salmonella and several pathotypes of E. coli) [28].

Studies concerning the association between enteric infections and oral cholera vaccine outcome have generally focused on specific pathogens. An inhibitory association between Helicobacter pylori colonization and CVD 103$\mathrm{HgR}$ response has been reported among Chilean children $<5$ years of age, but not in children aged 5-9 years [93]. Notably, this species is rarely documented among children $<1$ year of age, and is therefore unlikely to influence the immunogenicity of oral vaccines administered in early infancy [28,131]. During a placebo-controlled trial among 
6-13 year-old children in Ecuador who were infected with Ascaris lumbricoides, two doses of albendazole (an anthelmintic) prompted a modest improvement in immunogenicity following a subsequent dose of CVD 103$\mathrm{HgR}$ [92], though seroconversion rates in albendazole-treated children $(\sim 30 \%)$ still fell considerably short of those observed in North-American adults (>90\%) [139]. A subsequent trial in Ecuadorian teenagers revealed that $A$. lumbricoides inhibits Th1 cytokine responses (including IL-2 and IFN- $\gamma$ ) to CVD 103-HgR, and that albendazole treatment prior to vaccination partly reverses these effects [128]. However, deworming did not yield similar benefits for the immunogenicity of inactivated cholera vaccine among children in Bangladesh or Gabon [140,141].

Maternal helminth exposure may also be pertinent to infant vaccination outcomes. During a recent study in Ecuador in which OPV and Rotarix were administered according to routine schedules, infants exhibited higher plasma IgA levels for rotavirus and poliovirus if their mothers were infected with helminths in the last trimester of pregnancy [142]. Mechanisms underlying these effects are unclear, but may involve the transfer of helminth-induced cytokines (e.g., IL-10) across the placenta or in breast milk.

\section{The commensal microbiota}

The potential influence of the intestinal microbiota on oral vaccine response is not restricted to enteric pathogens. Colonization of the intestinal tract with commensal bacteria begins at birth [143]. The ensuing cross-talk between the bacterial microbiota and mucosal immune cells is critical to the development of the intestinal immune system, as evidenced by the gross deficits in immune function seen in germ-free mice [144]. Specific bacterial taxa may promote the expansion of particular immune cell subsets; for example, segmented filamentous bacteria trigger the accumulation of Th17 cells in the small intestine [145]. In addition to these effects on the developing immune system, the bacterial microbiota appears to facilitate the uptake and replication of a number of enteric viruses [146]. Depletion of commensal bacteria by antibiotics inhibits poliovirus replication and pathogenesis in mice [147], although this was not seen in human infants given therapeutic doses of azithromycin [28]. It has also been observed in vitro that poliovirus infectivity is enhanced by exposure to bacterial surface polysaccharides such as lipopolysaccharide and peptidoglycan [147], possibly via the effect of these polysaccharides on virion stability and receptor attachment [148]. Analogous effects have been reported for rotavirus, which exhibits reduced infectivity and pathogenicity (but greater immunogenicity) in antibiotic-treated mice [149].

While the intestinal microbiota plays a critical role in the development of the infant intestinal immune system, it is less clear whether variation in microbiota composition underlies variation in vaccine outcomes. The composition of the bacterial microbiota displays considerable variation by geographic setting [150-152], lifestyle [153] and season [154]. As such, the ecological landscape into which an oral vaccine is introduced is likely to vary considerably between infants in high- and low-income countries. To date, several observational studies have been performed in developing countries to examine the association between microbiota composition and oral vaccine response. OPV immunogenicity was positively correlated with the abundance of Actinobacteria (particularly the genus Bifidobacterium) among infants in Bangladesh [155]. In rural Ghana, Rotarix immunogenicity was associated with a lower abundance of Bacteroidetes and a greater abundance of Bacilli (specifically Streptococcus bovis) at 6 weeks of age, while infants who seroconverted exhibited an overall microbiota profile more similar to that of Dutch infants compared with nonresponders [156]. However, no comparable discrepancies in pre-vaccination microbiota composition were observed according to rotavirus or poliovirus seroconversion status among infants in India who received Rotarix and OPV at 6 and 10 weeks of age [157]. Thus, a consistent link between microbiota composition and oral vaccine performance has not yet been identified, and there is limited evidence to suggest that vaccine failure is associated with overt perturbations in the microbiota (or 'dysbiosis').

In addition to observational studies of microbiota composition, several trials have examined whether augmenting the infant microbiota with probiotic supplements has the capacity to improve oral vaccine outcomes. To date, the potential benefits of this approach remain equivocal, as reviewed elsewhere [158]. However, the administration of daily supplements of Lactobacillus rhamnosus GG provoked a modest improvement in Rotarix immunogenicity during a placebo-controlled trial in India [120]. As our understanding of the infant microbiota develops, microbiota-directed therapies may offer novel ways of boosting oral vaccine efficacy.

Additional studies exploring the relationship between commensal bacteria and oral vaccine response are likely to accumulate swiftly over the coming years. The potential impact of viral and eukaryotic components of the intestinal microbiota on oral vaccine outcome also merits further exploration (e.g., via shotgun sequencing of the metagenome), as does the metabolic output of the gut microbiota (the metabolome). Ultimately, potential associations will need to be validated using animal or in vitro organoid models. For example, gnotobiotic animals 
with a humanized gut microbiota have been used to test causal relationships between microbiota composition and disease states such as kwashiorkor [159] and inflammatory bowel disease [160]. This approach was recently applied to the phenomenon of oral vaccine failure by inoculating 24 newborn pigs with the fecal microbiota of a RotaTeq nonresponder with a high enteropathy score or a RotaTeq responder with a low enteropathy score (both from a study in Nicaragua) [161]. Although this approach failed to induce the manifestations of enteropathy (described below), pigs in the latter group exhibited stronger rotavirus-specific T-cell responses in the ileum, spleen and blood, and a reduction in the incidence of viral shedding and diarrhea after rotavirus challenge.

\section{Environmental enteric dysfunction}

Environmental enteric dysfunction (EED) - also referred to as 'environmental enteropathy' - is a subclinical disorder characterized by the flattening of intestinal villi, nutrient malabsorption, intestinal inflammation (including an influx of inflammatory cells into the lamina propria) and increased gut permeability $[162,163]$. These manifestations may begin to appear soon after birth: during a study in India, the majority of infants displayed some degree of villous blunting within the first 30 days of life [164]. The precise etiology of EED is unclear; however, it appears to be associated with poor environmental conditions, and in a murine model, inadequate diet and repeated microbial exposure were sufficient to promote the features of EED [165].

Owing to its pervasive nature in developing countries and the changes in intestinal immune function with which it is likely associated, EED has been hypothesized to play a key role in shaping geographic trends in oral vaccine performance $[162,166,167]$. Specific inhibitory effects might include the induction of a hostile pro-inflammatory state in the small intestine, the increased production of short-chain fatty acids or other immunomodulatory molecules that are inhibitory to oral vaccines, and the dampening of immune responses due to alterations in regulatory T-cell or dendritic-cell function [168].

In addition to its occurrence in developing countries, EED can also show seasonal variation, consistent with patterns of OPV immunogenicity [169]. However, a key difficulty faced by studies attempting to elucidate the impact of EED on oral vaccine outcome has been how best to measure and define the condition. Owing to the invasive nature of intestinal biopsies, studies of EED have tended to rely on serum and fecal biomarkers, such as those indicative of small bowel bacterial overgrowth (e.g., hydrogen breath test), gut inflammation (e.g., fecal calprotectin and myeloperoxidase), microbial translocation (e.g., serum EndoCab) and mucosal permeability (e.g., lactulose/mannitol test). To date, the study of these biomarkers has failed to yield any consistent associations between EED and oral vaccine performance [28,98,170-173], as discussed in detail elsewhere [CHURCH ET AL., IN Preparation].

The relative importance of EED in shaping the immune response to oral vaccines thus remains uncertain. It is possible that the ubiquitous nature of EED in developing countries is partly responsible for this. Indeed, in several of the studies that have examined the potential association between EED and oral vaccine outcome, the majority of infants displayed elevated levels for at least one inflammatory biomarker compared with those observed in high-income countries, and it would therefore be possible to classify nearly all vaccine recipients as having some degree of EED $[28,171]$. In such populations, EED may contribute to oral vaccine failure despite the absence of consistent correlations between individual biomarkers and vaccine outcome. Such homogeneity within study populations presents a considerable challenge to identifying whether individual-level EED or specific biomarkers are associated with vaccine response.

\section{Transmission intensity \& strain diversity of the infectious agent Pre-vaccination exposure}

The transmission intensity of enteric pathogens varies considerably by region. If natural exposure precedes vaccination, this may induce systemic and/or local immunity that impairs vaccine immunogenicity. In the case of rotavirus, exposure to natural infection in the neonatal period is common in settings with a high transmission intensity, and appears to be greatest at times of year associated with impaired vaccine immunogenicity [23]. In a review of Rotarix trials, baseline rotavirus-specific IgA seropositivity (indicative of prior virus exposure) was rare in studies performed in Europe and North America but was observed in up to $26 \%$ of participants in higher-burden settings [174]. A reduction in vaccine immunogenicity among infants positive for rotavirus-specific IgA was recently observed during studies of Rotarix conducted in Zambia [23], Bangladesh [135] and South Africa [36], but not in India [175]. Pre-vaccination exposure seems to have a similar effect on the immunogenicity of oral cholera vaccines, including both live-attenuated $[11,93,176]$ and inactivated vaccines $[96,177,178]$. Together, these findings suggest that the induc- 
tion of immunity following a previous encounter with a pathogen may contribute to the impaired immunogenicity of oral vaccines in high-transmission settings. Although potentially relevant in the past, pre-vaccination exposure is unlikely to influence OPV outcomes today given that individuals in endemic settings are typically immunized at birth and regularly thereafter (and thus prior to potential wild-type virus exposure).

\section{Post-vaccination exposure}

The nature of post-vaccination exposure to the targeted pathogen may also be pertinent to geographic variation in the protective efficacy of oral vaccines. Oral rotavirus vaccines confer homotypic and heterotypic protection against a wide variety of rotavirus genotypes $[179,180]$. However, as demonstrated in a range of settings, this protection appears to be lower against fully heterotypic strains (i.e., differing from the vaccine at both G and P epitopes) [181,182]. Such exposures may be more frequent in low-income countries, where the circulation of unusual rotavirus strains is more common $[183,184]$.

In addition to strain diversity, variation in transmission intensity may be a relevant factor. Following a trial of Ty21a in Indonesia, the authors suggested that an increase in the infectious inoculum ("more frequent inoculations of greater numbers of bacteria") in this high-transmission setting may have contributed to the lower efficacy observed in comparison to earlier trials in Chile and Egypt [185]. Similarly, an increase in infectious load following extensive flooding was implicated during a large outbreak of paralytic poliomyelitis within a highly immunized population in South Africa between 1987 and 1988 [186]. These hypotheses rest on the assumption that for a given level of vaccine-induced immunity there can be a 'breakthrough dose' that is capable of causing infection. In support of this idea, increasing the viral titer of OPV has been shown to increase the likelihood of infection among previously vaccinated individuals $[187,188]$. Comparable data for cholera and rotavirus infection are lacking.

\section{Conclusion \& future perspective}

Deficits in the immunogenicity of oral vaccines targeting poliovirus, rotavirus and several other enteric pathogens have consistently been documented in settings where they might have the greatest benefit. Despite considerable effort, we are yet to fully determine the biological mechanisms responsible for this phenomenon, let alone how best to circumvent it.

In Figure 4, we provide a qualitative synthesis of the literature on oral vaccine failure. Effect sizes are a notable omission from this table, and several associations would benefit from a dedicated systematic review and metaanalysis. Nonetheless, a number of conclusions can be drawn. Several risk factors for oral vaccine failure appear to have a consistent effect across multiple viral or bacterial vaccines, including passively acquired maternal antibodies and prior natural exposure to the vaccine target. Other risk factors may be unique to specific vaccines; for example, while co-administration with OPV may impair the response to live-attenuated oral rotavirus vaccines, OPV is robust to the effects of co-administration. Meanwhile, concurrent viral pathogens clearly inhibit OPV, and the same may be true of oral rotavirus vaccine. Finally, a consistent effect has not been forthcoming for risk factors such as EED and dysbiosis of the bacterial microbiota, perhaps owing to the ubiquitous nature of these conditions in settings associated with oral vaccine failure. It is also important to highlight that the mechanisms considered in this review do not occur in isolation. Consider, for example, the interconnected nature of enteric pathogen exposure, EED, bacterial microbiota composition and malnutrition, among others. Although we have discussed the evidence behind individual risk factors for oral vaccine failure separately, in reality these factors may combine to induce a state of immune hyporesponsiveness.

The impaired performance of oral vaccines does not negate their benefits. Indeed, a partially effective vaccine in a high-burden setting may prevent many more cases than a completely effective vaccine in a low-burden setting. In countries such as Botswana and Zambia, the delivery of rotavirus vaccines in routine immunization programs has been accompanied by 20-30\% declines in diarrhea-related hospitalizations and deaths [189,190], and the continued roll-out of rotavirus vaccines elsewhere is likely to bring about comparable benefits to public health.

Yet in spite of these benefits, the issue of impaired vaccine performance in resource-poor settings lingers on. Overcoming this problem may require the development of novel vaccine formulations or interventions to improve the immune response to existing vaccines, such as changes in scheduling, the delivery of additional doses (e.g., a birth dose of rotavirus vaccine), increases in vaccine titer, or administration of immunomodulatory drugs or antior pro-biotics. So far, such interventions have had mixed results and none have offered a clear advantage that has translated into policy (with perhaps the exception of increasing the number of vaccine doses administered for OPV). A systematic review of these interventions is beyond the scope of this manuscript, but is currently underway [191]. 


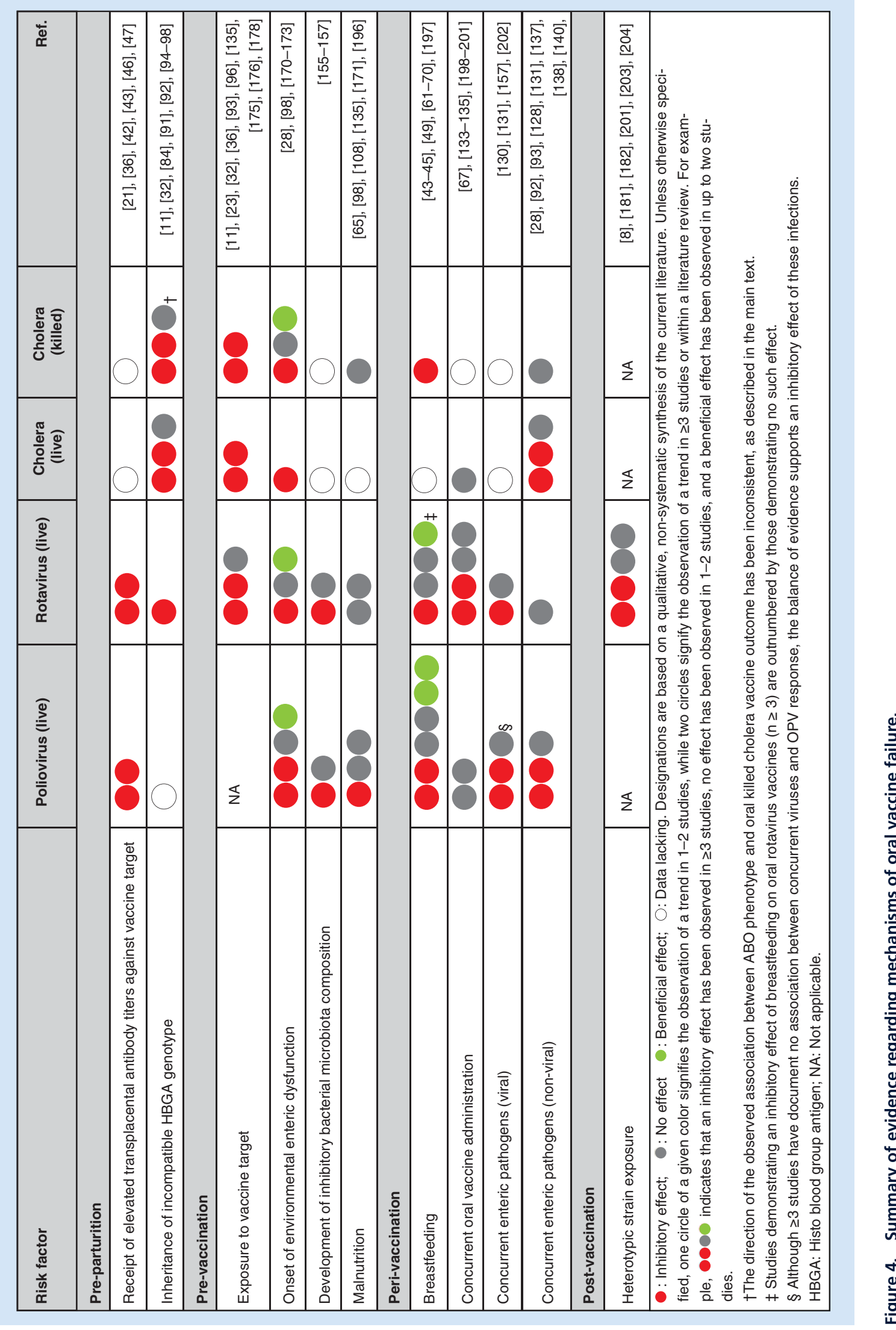


Notably, in the case of rotavirus, serum IgA is typically measured during studies of vaccine immunogenicity, but is an imperfect correlate of protection [192]. The identification of new correlates of protection may precipitate an improved understanding of the factors that shape vaccine performance.

We are in the midst of a period of profound change in the use of oral vaccines. OPV has formed the foundation of global efforts to eradicate poliomyelitis and has taught us much regarding the mechanisms that shape oral vaccine efficacy. However, it must eventually be phased out from all immunization activities to prevent the emergence of vaccine-derived polioviruses [193] - a process that began with the replacement of trivalent with bivalent OPV (lacking serotype 2) in April 2016. It appears likely that polio eradication will be achieved in spite of the impaired immunogenicity of OPV. On the other hand, the global roll-out of oral rotavirus vaccine continues, and the impaired performance of rotavirus vaccines in resource-poor settings is likely to gain ever-greater prominence as immunization efforts expand. Improving our understanding of the determinants of oral vaccine immunogenicity

\section{Executive summary}

Poor immunogenicity \& efficacy of oral vaccines in low-income countries

- Oral vaccines against rotavirus, poliovirus, cholera and typhoid are currently licensed.

- They are easy to administer and induce protective mucosal immunity against infection and disease.

- However, they have consistently proven to be less immunogenic and efficacious in low-income countries, limiting their effectiveness and impact. The reasons for this phenomenon have not been fully elucidated.

Potential explanations \& underlying mechanisms

- In infancy, transplacental or breast milk antibodies specific to the vaccine may interfere with immunogenicity. IgA in breast milk may neutralize vaccine virus or limit colonization by bacterial vaccine strains, while transplacental IgG in infant serum can interfere with both oral and parenteral vaccine immunogenicity through mechanisms that remain unclear.

- Histo blood group antigens in breast milk and epithelial cell secretions can bind vaccine virus, potentially facilitating or blocking replication and immunogenicity.

- Other human genetic polymorphisms associated with oral vaccine immunogenicity have not been clearly identified.

- Intestinal infection with bacterial, viral and eukaryotic pathogens may induce an innate immune response that inhibits replication of the vaccine strain and suppresses a systemic immune response. Their significance remains unclear, although enterovirus infections have been clearly shown to reduce oral poliovirus vaccine immunogenicity.

- Environmental enteropathy is found in infants in low-income countries as a result of frequent exposure to intestinal pathogens and is characterized by intestinal inflammation, increased permeability and microbial translocation. These may contribute to oral vaccine failure, but biomarkers of enteropathy have not shown consistent associations with oral vaccine immunogenicity.

- Malnutrition and micronutrient deficiencies occur in populations where oral vaccine immunogenicity is diminished, but measures of malnutrition and growth of infants do not appear to be directly associated with immunogenicity.

- Pre-vaccination exposure to the pathogen or the size of the infectious challenge dose post vaccination may limit vaccine effectiveness in low-income countries, but evidence in support of this hypothesis is limited.

\section{Interventions}

- Insights from studies of the mechanisms responsible for poor oral vaccine immunogenicity have so far failed to yield effective interventions to improve immunogenicity or better-designed vaccines.

- Increases in the number of doses of vaccine given have in some cases led to improvements in immunogenicity and efficacy (e.g., oral poliovirus vaccine).

- Withholding breastfeeding has not significantly improved the immunogenicity of oral poliovirus, rotavirus or cholera vaccines.

- Treatment of enteropathy and supplementation with micronutrients or probiotics have not consistently resulted in improvements in oral vaccine immunogenicity.

Conclusion

- Oral vaccines are among the more cost-effective health interventions, but their impact is not fully realized because of diminished immunogenicity and efficacy in the populations that need them most.

- We remain uncertain about the mechanisms responsible for diminished immunogenicity, although new studies and technologies are providing unprecedented insights. Some mechanisms may be general, applying to all oral vaccines, while others may apply only to specific vaccines.

- Intervention studies aimed at improving oral vaccine immunogenicity need to account for vaccine-specific mechanisms. Such trials are needed in order to move beyond studies of association only. 
will be key to maximizing the impact of licensed oral vaccines as well as stimulating development of this route of immunization in the context of a crowded parenteral schedule.

\section{Acknowledgements}

The authors are grateful to R Sarkar for his help during the planning of this review.

\section{Financial \& competing interests disclosure}

EPK Parker has received funding from the UK Medical Research Council. M Iturriza-Gómara has received research grant support form GlaxoSmithKline and Sanofi Pasteur MSD. The authors have no other relevant affiliations or financial involvement with any organization or entity with a financial interest in or financial conflict with the subject matter or materials discussed in the manuscript. This includes employment, consultancies, honoraria, stock ownership or options, expert testimony, grants or patents received or pending, or royalties.

No writing assistance was utilized in the production of this manuscript.

\section{Open access}

This work is licensed under the Attribution-NonCommercial-NoDerivatives 4.0 Unported License. To view a copy of this license, visit http://creativecommons.org/licenses/by-nc-nd/4.0/.

\section{References}

Papers of special note have been highlighted as: $\bullet \bullet$ of considerable interest

1 Liu L, Johnson HL, Cousens S et al. Global, regional, and national causes of child mortality: an updated systematic analysis for 2010 with time trends since 2000. Lancet 379(9832), 2151-2161 (2012).

2 Kotloff KL, Nataro JP, Blackwelder WC et al. Burden and aetiology of diarrhoeal disease in infants and young children in developing countries (the Global Enteric Multicenter Study, GEMS): a prospective, case-control study. Lancet 382(9888), 209-222 (2013).

3 Holmgren J, Czerkinsky C. Mucosal immunity and vaccines. Nat. Med. 11(Suppl. 4), S45-S53 (2005).

4 Pollard SL, Malpica-Llanos T, Friberg IK, Fischer-Walker C, Ashraf S, Walker N. Estimating the herd immunity effect of rotavirus vaccine. Vaccine 33(32), 3795-3800 (2015).

5 Bines JE, Danchin M, Jackson P et al. Safety and immunogenicity of RV3-BB human neonatal rotavirus vaccine administered at birth or in infancy: a randomised, double-blind, placebo-controlled trial. Lancet Infect. Dis. 15(12), 1389-1397 (2015).

6 Isanaka S, Guindo O, Langendorf C et al. Efficacy of a low-cost, heat-stable oral rotavirus vaccine in Niger. N. Engl. J. Med. 376(12), $1121-1130$ (2017).

7 Vesikari T, Karvonen A, Prymula R et al. Efficacy of human rotavirus vaccine against rotavirus gastroenteritis during the first 2 years of life in European infants: randomised, double-blind controlled study. Lancet 370(9601), 1757-1763 (2007).

8 Madhi SA, Cunliffe NA, Steele D et al. Effect of human rotavirus vaccine on severe diarrhea in African infants. N. Engl. J. Med. 362(4), 289-298 (2010).

9 Suharyono, Simanjuntak C, Witham N et al. Safety and immunogenicity of single-dose live oral cholera vaccine CVD 103-HgR in 5-9 year-old Indonesian children. Lancet 340(8821), 689-694 (1992).

10 Gotuzzo E, Butron B, Seas C et al. Safety, immunogenicity, and excretion pattern of single-dose live oral cholera vaccine CVD 103-HgR in Peruvian adults of high and low socioeconomic levels. Infect. Immun. 61(9), 3994-3997 (1993).

11 Richie EE, Punjabi NH, Sidharta YY et al. Efficacy trial of single-dose live oral cholera vaccine CVD 103-HgR in North Jakarta, Indonesia, a cholera-endemic area. Vaccine 18(22), 2399-2410 (2000).

12 Patriarca PA, Wright PF, John TJ. Factors affecting the immunogenicity of oral poliovirus vaccine in developing countries: review. Rev. Infect. Dis. 13(5), 926-939 (1991).

-. Summarizes trials of oral poliovirus vaccine (OPV) immunogenicity in developing countries.

13 Anwar E, Goldberg E, Fraser A, Acosta CJ, Paul M, Leibovici L. Vaccines for preventing typhoid fever. Cochrane Database Syst. Rev. 1, CD001261 (2014).

14 Gilman RH, Hornick RB, Woodard WE et al. Evaluation of a UDP-glucose-4-epimeraseless mutant of Salmonella typhi as a liver oral vaccine. J. Infect. Dis. 136(6), 717-723 (1977).

15 Darton TC, Jones C, Blohmke CJ et al. Using a human challenge model of infection to measure vaccine efficacy: a randomised, controlled trial comparing the typhoid vaccines M01ZH09 with placebo and Ty21a. PLoS Negl. Trop. Dis. 10(8), e0004926 (2016).

16 WHO. Future needs and directions for Shigella vaccines. Wkly Epidemiol. Rec. 81(6), 51-58 (2006).

17 Levine MM, Kotloff KL, Barry EM, Pasetti MF, Sztein MB. Clinical trials of Shigella vaccines: two steps forward and one step back on a long, hard road. Nat. Rev. Microbiol. 5(7), 540-553 (2007). 
18 Hallander HO, Paniagua M, Espinoza F et al. Calibrated serological techniques demonstrate significant different serum response rates to an oral killed cholera vaccine between Swedish and Nicaraguan children. Vaccine 21(1-2), 138-145 (2002).

19 Capeding MR, Cadorna-Carlos J, Book-Montellano M, Ortiz E. Immunogenicity and safety of a DTaP-IPV//PRP approximately T combination vaccine given with hepatitis B vaccine: a randomized open-label trial. Bull. World Health Organ. 86(6), 443-451 (2008).

20 Rusmil K, Gunardi H, Fadlyana E et al. The immunogenicity, safety, and consistency of an Indonesia combined DTP-HB-Hib vaccine in expanded program on immunization schedule. BMC Pediatr. 15, 219 (2015).

21 Cirne MD, Duarte M, Nobrega DD et al. Factors affecting the immunogenicity of oral poliovirus vaccine: a prospective evaluation in Brazil and the Gambia. J. Infect. Dis. 171(5), 1097-1106 (1995).

22 Grassly NC, Jafari H, Bahl S et al. Waning intestinal immunity after vaccination with oral poliovirus vaccines in India. J. Infect. Dis. 205(10), 1554-1561 (2012).

-• Demonstrates the strong seasonality in OPV replication efficiency among children in India.

23 Chilengi R, Simuyandi M, Beach L et al. Association of maternal immunity with rotavirus vaccine immunogenicity in Zambian infants. PloS ONE 11(3), e0150100 (2016).

24 Halsey N, Galazka A. The efficacy of DPT and oral poliomyelitis immunization schedules initiated from birth to 12 weeks of age. Bull. World Health Organ. 63(6), 1151-1169 (1985).

25 Mateen FJ, Shinohara RT, Sutter RW. Oral and inactivated poliovirus vaccines in the newborn: a review. Vaccine 31(21), 2517-2524 (2013).

26 Ali SA, Kazi AM, Cortese MM et al. Impact of different dosing schedules on the immunogenicity of the human rotavirus vaccine in infants in Pakistan: a randomized trial. J. Infect. Dis. 210(11), 1772-1779 (2014).

27 Armah G, Lewis $\mathrm{KD}$, Cortese MM et al. A randomized, controlled trial of the impact of alternative dosing schedules on the immune response to human rotavirus vaccine in rural Ghanaian infants. J. Infect. Dis. 213(11), 1678-1685 (2016).

28 Grassly NC, Praharaj I, Babji S et al. The effect of azithromycin on the immunogenicity of oral poliovirus vaccine: a double-blind randomised placebo-controlled trial in seronegative Indian infants. Lancet Infect. Dis. 16(8), 905-914 (2016).

29 Simanjuntak $\mathrm{CH}$, O’Hanley P, Punjabi NH et al. Safety, immunogenicity, and transmissibility of single-dose live oral cholera vaccine strain CVD 103-HgR in 24- to 59 month-old Indonesian children. J. Infect. Dis. 168(5), 1169-1176 (1993).

30 Bhuiyan TR, Choudhury FK, Khanam F et al. Evaluation of immune responses to an oral typhoid vaccine, Ty21a, in children from 2 to 5 years of age in Bangladesh. Vaccine 32(9), 1055-1060 (2014).

31 Clemens JD, Sack DA, Harris JR et al. Field trial of oral cholera vaccines in Bangladesh: results from three-year follow-up. Lancet 335(8684), 270-273 (1990).

32 Saha A, Chowdhury MI, Khanam F et al. Safety and immunogenicity study of a killed bivalent (O1 and O139) whole-cell oral cholera vaccine Shanchol, in Bangladeshi adults and children as young as 1 year of age. Vaccine 29(46), 8285-8292 (2011).

33 Sur D, Kanungo S, Sah B et al. Efficacy of a low-cost, inactivated whole-cell oral cholera vaccine: results from 3 years of follow-up of a randomized, controlled trial. PLoS Negl. Trop. Dis. 5(10), e1289 (2011).

34 Qadri F, Wierzba TF, Ali M et al. Efficacy of a single-dose, inactivated oral cholera vaccine in Bangladesh. N. Engl. J. Med. 374(18), 1723-1732 (2016).

35 Da Silva MM, Prem KA, Johnson EA, McKelvey JL, Syverton JT. Response of pregnant women and their infants to poliomyelitis vaccine; distribution of poliovirus antibody in pregnant women before and after vaccination; transfer, persistence, and induction of antibodies in infants. J. Am. Med. Assoc. 168(1), 1-5 (1958).

36 Moon SS, Groome MJ, Velasquez DE et al. Prevaccination rotavirus serum IgG and IgA are associated with lower immunogenicity of live, oral human rotavirus vaccine in South African infants. Clin. Infect. Dis. 62(2), 157-165 (2016).

37 Cohen IR, Norins LC. Antibodies of the IgG, IgM, and IgA classes in newborn and adult sera reactive with Gram-negatvie bacteria. J. Clin. Invest. 57, 1053-1062 (1968).

38 Gelfand HM, Fox JP, Leblanc DR, Elveback L. Studies on the development of natural immunity to poliomyelitis in Louisiana. V. Passive transfer of polioantibody from mother to fetus, and natural decline and disappearance of antibody in the infant. J. Immunol. 85, 46-55 (1960).

39 Voysey M, Kelly DF, Fanshawe TR et al. The influence of maternally derived antibody and infant age at vaccination on infant vaccine responses: an individual participant meta-analysis. JAMA Pediatr. 171(7), 637-646 (2017).

-. Shows the inhibitory effect of maternal antibodies across a wide range of oral and parenteral vaccines.

40 Siegrist CA. Mechanisms by which maternal antibodies influence infant vaccine responses: review of hypotheses and definition of main determinants. Vaccine 21(24), 3406-3412 (2003).

41 Asturias EJ, Dueger EL, Omer SB et al. Randomized trial of inactivated and live polio vaccine schedules in Guatemalan infants. J. Infect. Dis. 196(5), 692-698 (2007).

42 Chandir S, Ahamed KU, Baqui AH et al. Effect of buffer on the immune response to trivalent oral poliovirus vaccine in Bangladesh: a community based randomized controlled trial. J. Infect. Dis. 210(Suppl. 1), S390-S397 (2014). 
43 Estivariz CF, Anand A, Gary HE Jr et al. Immunogenicity of three doses of bivalent, trivalent, or type 1 monovalent oral poliovirus vaccines with a 2 week interval between doses in Bangladesh: an open-label, non-inferiority, randomised, controlled trial. Lancet Infect. Dis. 15(8), 898-904 (2015).

44 Sabin AB, Michaels RH, Krugman S, Eiger ME, Berman PH, Warren J. Effect of oral poliovirus vaccine in newborn children. I. Excretion of virus after ingestion of large doses of type I or of mixture of all three types, in relation to level of placentally transmitted antibody. Pediatrics 31, 623-640 (1963).

45 Warren RJ, Lepow ML, Bartsch GE, Robbins FC. The relationship of maternal antibody, breast feeding, and age to the susceptibility of newborn infants to infection with attenuated polioviruses. Pediatrics 34, 4-13 (1964).

46 Becker-Dreps S, Vilchez S, Velasquez D et al. Rotavirus-specific IgG antibodies from mothers's serum may inhibit infant immune responses to the pentavalent rotavirus vaccine. Pediatr. Infect. Dis. J. 34(1), 115-116 (2015).

47 Appaiahgari MB, Glass R, Singh S et al. Transplacental rotavirus IgG interferes with immune response to live oral rotavirus vaccine ORV-116E in Indian infants. Vaccine 32(6), 651-656 (2014).

48 Gruber JF, Gruber LM, Weber RP, Becker-Dreps S, Jonsson Funk M. Rotavirus vaccine schedules and vaccine response among infants in low- and middle-income countries: a systematic review. Open Forum Infect. Dis. 4(2), ofx066 (2017).

49 Rongsen-Chandola T, Strand TA, Goyal N et al. Effect of withholding breastfeeding on the immune response to a live oral rotavirus vaccine in North Indian infants. Vaccine 32(Suppl. 1), A134-A139 (2014).

50 Chan J, Nirwati H, Triasih R et al. Maternal antibodies to rotavirus: could they interfere with live rotavirus vaccines in developing countries? Vaccine 29(6), 1242-1247 (2011).

51 John J, Abraham AM, Muliyil J, John TJ, Deshpande JM, Kang G. Gap in the prevalence of neutralising antibodies to polioviruses in antenatal women in southern India. Trans. R Soc. Trop. Med. Hyg. 105(3), 179-180 (2011).

52 Moro L, Bardaji A, Nhampossa T et al. Malaria and HIV infection in Mozambican pregnant women are associated with reduced transfer of antimalarial antibodies to their newborns. J. Infect. Dis. 211(6), 1004-1014 (2015).

53 Morrow AL, Ruiz-Palacios GM, Jiang X, Newburg DS. Human-milk glycans that inhibit pathogen binding protect breast-feeding infants against infectious diarrhea. J. Nutr. 135(5), 1304-1307 (2005).

54 Patel M, Shane AL, Parashar UD, Jiang B, Gentsch JR, Glass RI. Oral rotavirus vaccines: how well will they work where they are needed most? J. Infect. Dis. 200(Suppl. 1), S39-S48 (2009).

55 Moon SS, Wang Y, Shane AL et al. Inhibitory effect of breast milk on infectivity of live oral rotavirus vaccines. Pediatr. Infect. Dis. J. 29(10), 919-923 (2010).

56 Novak D, Svennerholm AM. A comparison of seasonal variations in rotavirus antibodies in the breast milk of Swedish and Bangladeshi mothers. Acta Paediatr. 104(3), 247-251 (2015)

57 Moon SS, Tate JE, Ray P et al. Differential profiles and inhibitory effect on rotavirus vaccines of nonantibody components in breast milk from mothers in developing and developed countries. Pediatr. Infect. Dis. J. 32(8), 863-870 (2013).

58 Becker-Dreps S, Choi WS, Stamper L et al. Innate immune factors in mothers' breast milk and their lack of association with rotavirus vaccine immunogenicity in Nicaraguan infants. J. Pediatr. Infect. Dis. Soc. 6(1), 87-90 (2017).

59 Zaman S, Carlsson B, Morikawa A et al. Poliovirus antibody titres, relative affinity, and neutralising capacity in maternal milk. Arch. Dis. Child. 68(2), 198-201 (1993).

60 Glass RI, Svennerholm AM, Stoll BJ et al. Protection against cholera in breast-fed children by antibodies in breast milk. N. Engl. J. Med. 308(23), 1389-1392 (1983).

61 Lepow ML, Warren RJ, Gray N, Ingram VG, Robbins FC. Effect of Sabin Type 1 poliomyelitis vaccine administered by mouth to newborn infants. N. Engl. J. Med. 264, 1071-1078 (1961).

62 Domok I, Balayan MS, Fayinka OA, Skrtic N, Soneji AD, Harland PS. Factors affecting the efficacy of live poliovirus vaccine in warm climates. Efficacy of type 1 Sabin vaccine administered together with antihuman gamma-globulin horse serum to breast-fed and artificially fed infants in Uganda. Bull. World Health Organ. 51(4), 333-347 (1974).

63 John TJ, Devarajan LV, Luther L, Vijayarathnam P. Effect of breast-feeding on seroresponse of infants to oral poliovirus vaccination. Pediatrics 57(1), 47-53 (1976).

64 Pickering LK, Granoff DM, Erickson JR et al. Modulation of the immune system by human milk and infant formula containing nucleotides. Pediatrics 101(2), 242-249 (1998).

65 Haque R, Snider C, Liu Y et al. Oral polio vaccine response in breast fed infants with malnutrition and diarrhea. Vaccine 32(4), 478-482 (2014).

66 Pichichero ME. Effect of breast-feeding on oral rhesus rotavirus vaccine seroconversion: a metaanalysis. J. Infect. Dis. 162(3), 753-755 (1990).

67 Rennels MB. Influence of breast-feeding and oral poliovirus vaccine on the immunogenicity and efficacy of rotavirus vaccines. J. Infect. Dis. 174(Suppl. 1), S107-S111 (1996). 
68 Groome MJ, Moon SS, Velasquez D et al. Effect of breastfeeding on immunogenicity of oral live-attenuated human rotavirus vaccine: a randomized trial in HIV-uninfected infants in Soweto, South Africa. Bull. World Health Organ. 92(4), 238-245 (2014).

-• One of several randomized trials to show no beneficial effect of temporarily withholding breastfeeding on oral rotavirus vaccine immunogenicity.

69 Ali A, Kazi AM, Cortese MM et al. Impact of withholding breastfeeding at the time of vaccination on the immunogenicity of oral rotavirus vaccine - a randomized trial. PLoS ONE 10(6), e0127622 (2015).

70 Ahmed T, Svennerholm AM, Al Tarique A, Sultana GN, Qadri F. Enhanced immunogenicity of an oral inactivated cholera vaccine in infants in Bangladesh obtained by zinc supplementation and by temporary withholding breast-feeding. Vaccine 27(9), 1433-1439 (2009).

71 Bilenko N, Ghosh R, Levy A, Deckelbaum RJ, Fraser D. Partial breastfeeding protects Bedouin infants from infection and morbidity: prospective cohort study. Asia Pac. J. Clin. Nutr. 17(2), 243-249 (2008).

72 M'Rabet L, Vos AP, Boehm G, Garssen J. Breast-feeding and its role in early development of the immune system in infants: consequences for health later in life. J. Nutr. 138(9), 1782S-1790S (2008).

73 Newport MJ, Goetghebuer T, Weiss HA et al. Genetic regulation of immune responses to vaccines in early life. Genes Immun. 5(2), 122-129 (2004).

74 Flores J, Okhuysen PC. Genetics of susceptibility to infection with enteric pathogens. Curr. Opin. Infect. Dis. 22(5), 471-476 (2009).

75 Kambhampati A, Payne DC, Costantini V, Lopman BA. Host genetic susceptibility to enteric viruses: a systematic review and metaanalysis. Clin. Infect. Dis. 62(1), 11-18 (2016).

-. Demonstrates the strong strain-specific differences in norovirus and rotavirus susceptibility that have been observed according to histo blood group antigen phenotype.

$76 \mathrm{Hu}$ L, Crawford SE, Czako R et al. Cell attachment protein VP8* of a human rotavirus specifically interacts with A-type histo-blood group antigen. Nature 485(7397), 256-259 (2012).

77 Huang P, Xia M, Tan M et al. Spike protein VP8* of human rotavirus recognizes histo-blood group antigens in a type-specific manner. J. Virol. 86(9), 4833-4843 (2012).

78 Nordgren J, Sharma S, Bucardo F et al. Both Lewis and secretor status mediate susceptibility to rotavirus infections in a rotavirus genotype-dependent manner. Clin. Infect. Dis. 59(11), 1567-1573 (2014).

79 Ayouni S, Sdiri-Loulizi K, De Rougemont A et al. Rotavirus P [8] infections in persons with secretor and nonsecretor phenotypes, Tunisia. Emerg. Infect. Dis. 21(11), 2055-2058 (2015).

80 Akhter S, Kibria GM, Akhter NR, Habibullah MM, Islam SMK, Zakariah M. ABO and Lewis blood grouping with ABH secretor and non-secretor status: a cross sectional study in Dhaka. Faridpur Med. Coll. J. 6(1) 38-40 (2011).

81 Saboor M, Ullah A, Qamar K, Mir A, Moinuddin. Frequency of ABH secretors and non secretors: a cross sectional study in Karachi. Pak. J. Med. Sci. 30(1), 189-193 (2014).

82 Devi AS, Meera T, Singh KP, Nabachandra H, Shah I. Secretors in Manipuri population: a study. J. Indian Acad. Forensic Med. 37(2), 127-130 (2015).

83 Nordgren J, Nitiema LW, Ouermi D, Simpore J, Svensson L. Host genetic factors affect susceptibility to norovirus infections in Burkina Faso. PLoS ONE 8(7), e69557 (2013).

84 Kazi AM, Cortese MM, Yu Y et al. Secretor and salivary ABO blood group antigen status predict rotavirus vaccine take in infants. J. Infect. Dis. 215(5), 786-789 (2017).

85 El-Deeb H, El-Rafie M. Clinically diagnosed poliomyelitis in a presumably vaccinated population. Gaz Egypt Paediatr. Assoc. 23(2), 161-166 (1975).

86 Boren T, Falk P, Roth KA, Larson G, Normark S. Attachment of Helicobacter pylori to human gastric epithelium mediated by blood group antigens. Science 262(5141), 1892-1895 (1993).

87 Qadri F, Saha A, Ahmed T, Al Tarique A, Begum YA, Svennerholm AM. Disease burden due to enterotoxigenic Escherichia coli in the first 2 years of life in an urban community in Bangladesh. Infect. Immun. 75(8), 3961-3968 (2007).

88 Levine MM, Nalin DR, Rennels MB et al. Genetic susceptibility to cholera. Ann. Hum. Biol. 6(4), 369-374 (1979).

89 Harris JB, Khan AI, Larocque RC et al. Blood group, immunity, and risk of infection with Vibrio cholerae in an area of endemicity. Infect. Immun. 73(11), 7422-7427 (2005).

90 Chaudhuri A, Dasadhikary CR. Possible role of blood-group secretory substances in the aetiology of cholera. Trans. R Soc. Trop. Med. Hyg. 72(6), 664-665 (1978).

91 Lagos R, Avendano A, Prado V et al. Attenuated live cholera vaccine strain CVD 103-HgR elicits significantly higher serum vibriocidal antibody titers in persons of blood group O. Infect. Immun. 63(2), 707-709 (1995).

92 Cooper PJ, Chico ME, Losonsky G et al. Albendazole treatment of children with ascariasis enhances the vibriocidal antibody response to the live attenuated oral cholera vaccine CVD 103-HgR. J. Infect. Dis. 182(4), 1199-1206 (2000). 
93 Muhsen K, Lagos R, Reymann MK, Graham DY, Pasetti MF, Levine MM. Age-dependent association among Helicobacter pylori infection, serum pepsinogen levels and immune response of children to live oral cholera vaccine CVD 103-HgR. PLoS ONE 9(1), e83999 (2014).

94 Chen WH, Greenberg RN, Pasetti MF et al. Safety and immunogenicity of single-dose live oral cholera vaccine strain CVD 103-HgR, prepared from new master and working cell banks. Clin. Vaccine Immunol. 21(1), 66-73 (2014).

95 Clemens JD, Sack DA, Harris JR et al. ABO blood groups and cholera: new observations on specificity of risk and modification of vaccine efficacy. J. Infect. Dis. 159(4), 770-773 (1989).

96 Charles RC, Hilaire IJ, Mayo-Smith LM et al. Immunogenicity of a killed bivalent (O1 and O139) whole cell oral cholera vaccine, Shanchol, in Haiti. PLoS Negl. Trop. Dis. 8(5), e2828 (2014).

97 Ramamurthy T, Wagener D, Chowdhury G, Majumder PP. A large study on immunological response to a whole-cell killed oral cholera vaccine reveals that there are significant geographical differences in response and that $\mathrm{O}$ blood group individuals do not elicit a higher response. Clin. Vaccine Immunol. 17(8), 1232-1237 (2010).

98 Uddin MI, Islam S, Nishat NS et al. Biomarkers of environmental enteropathy are positively associated with immune responses to an oral Cholera vaccine in Bangladeshi children. PLoS Negl. Trop. Dis. 10(11), e0005039 (2016).

99 Nathalang O, Kuvanont S, Punyaprasiddhi P, Tasaniyanonda C, Sriphaisal T. A preliminary study of the distribution of blood group systems in Thai blood donors determined by the gel test. Southeast Asian J. Trop. Med. Public Health 32(1), 204-207 (2001).

100 Charbonneau MR, O’Donnell D, Blanton LV et al. Sialylated milk oligosaccharides promote microbiota-dependent growth in models of infant undernutrition. Cell 164(5), 859-871 (2016).

101 Lewis ZT, Totten SM, Smilowitz JT et al. Maternal fucosyltransferase 2 status affects the gut bifidobacterial communities of breastfed infants. Microbiome 3, 13 (2015).

102 Rodriguez-Diaz J, Garcia-Mantrana I, Vila-Vicent S et al. Relevance of secretor status genotype and microbiota composition in susceptibility to rotavirus and norovirus infections in humans. Sci. Rep. 7, 45559 (2017).

103 Mentzer AJ, O'Connor D, Pollard AJ, Hill AV. Searching for the human genetic factors standing in the way of universally effective vaccines. Philos. Trans. R Soc. Lond. B Biol. Sci. 370(1671), pii:20140341 (2015).

104 Milet J, Sabbagh A, Migot-Nabias F et al. Genome-wide association study of antibody responses to Plasmodium falciparum candidate vaccine antigens. Genes Immun. 17(2), 110-117 (2016).

105 Wojcik GL. The Genomics of Oral Poliovirus Vaccine Response in Bangladeshi Infants (2013). https://jscholarship.library.jhu.edu/handle/1774.2/37070

106 Caulfield LE, De Onis M, Blossner M, Black RE. Undernutrition as an underlying cause of child deaths associated with diarrhea, pneumonia, malaria, and measles. Am. J. Clin. Nutr. 80(1), 193-198 (2004).

107 Rytter MJ, Kolte L, Briend A, Friis H, Christensen VB. The immune system in children with malnutrition - a systematic review. PLoS ONE 9(8), e105017 (2014).

108 Savy M, Edmond K, Fine PE et al. Landscape analysis of interactions between nutrition and vaccine responses in children. J. Nutr. 139(11), 2154S-2218S (2009).

-• Comprehensively reviews studies examining the association between various measures of malnutrition and vaccine response.

109 Prendergast AJ. Malnutrition and vaccination in developing countries. Philos. Trans. R Soc. Lond. B Biol. Sci. 370(1671), pii:20140141 (2015).

110 Greenwood BM, Bradley-Moore AM, Bradley AK, Kirkwood BR, Gilles HM. The immune response to vaccination in undernourished and well-nourished Nigerian children. Ann. Trop. Med. Parasitol. 80(5), 537-544 (1986).

111 Chopra K, Kundu S, Chowdhury DS. Antibody response of infants in tropics to five doses of oral polio vaccine. J. Trop. Pediatr. 35(1), 19-23 (1989).

112 Saleem AF, Mach O, Quadri F et al. Immunogenicity of poliovirus vaccines in chronically malnourished infants: a randomized controlled trial in Pakistan. Vaccine 33(24), 2757-2763 (2015).

113 Rahman MM, Alvarez JO, Mahalanabis D et al. Effect of vitamin A administration on response to oral polio vaccination. Nutr. Res. 18(7), 1125-1133 (1998)

114 Semba RD, Muhilal, Mohgaddam NE et al. Integration of vitamin A supplementation with the expanded program on immunization does not affect seroconversion to oral poliovirus vaccine in infants. J. Nutr. 129(12), 2203-2205 (1999).

115 Newton S, Cousens S, Owusu-Agyei S et al. Vitamin A supplementation does not affect infants' immune responses to polio and tetanus vaccines. J. Nutr. 135(11), 2669-2673 (2005).

116 Patro B, Golicki D, Szajewska H. Meta-analysis: zinc supplementation for acute gastroenteritis in children. Aliment Pharmacol. Ther. 28(6), 713-723 (2008).

117 Habib MA, Soofi S, Sheraz A et al. Zinc supplementation fails to increase the immunogenicity of oral poliovirus vaccine: a randomized controlled trial. Vaccine 33(6), 819-825 (2015). 
118 Albert MJ, Qadri F, Wahed MA et al. Supplementation with zinc, but not vitamin A, improves seroconversion to vibriocidal antibody in children given an oral cholera vaccine. J. Infect. Dis. 187(6), 909-913 (2003).

119 Colgate ER, Haque R, Dickson DM et al. Delayed dosing of oral rotavirus vaccine demonstrates decreased risk of rotavirus gastroenteritis associated with serum zinc: a randomized controlled trial. Clin. Infect. Dis. 63(5), 634-641 (2016).

120 Lazarus RP, John J, Shanmugasundaram E et al. A randomized, double blind, placebo controlled trial of supplementation with zinc and/or probiotics to enhance the immune response of oral rotavirus and polio vaccines in Indian infants. Vaccine doi:10.1016/j.vaccine.2017.07.116 (2017) (Epub head of print).

121 Brown KH, Black RE, Becker S. Seasonal changes in nutritional status and the prevalence of malnutrition in a longitudinal study of young children in rural Bangladesh. Am. J. Clin. Nutr. 36(2), 303-313 (1982).

122 Campbell DI, Elia M, Lunn PG. Growth faltering in rural Gambian infants is associated with impaired small intestinal barrier function, leading to endotoxemia and systemic inflammation. J. Nutr. 133(5), 1332-1338 (2003).

123 Platts-Mills JA, Taniuchi M, Uddin MJ et al. Association between enteropathogens and malnutrition in children aged 6-23 mo in Bangladesh: a case-control study. Am. J. Clin. Nutr. 105(5), 1132-1138 (2017).

124 Platts-Mills JA, Babji S, Bodhidatta L et al. Pathogen-specific burdens of community diarrhoea in developing countries: a multisite birth cohort study (MAL-ED). Lancet Glob. Health 3(9), e564-e575 (2015).

125 Crouse J, Kalinke U, Oxenius A. Regulation of antiviral T cell responses by type I interferons. Nat. Rev. Immunol. 15(4), 231-242 (2015).

126 Saxena K, Simon LM, Zeng XL et al. A paradox of transcriptional and functional innate interferon responses of human intestinal enteroids to enteric virus infection. Proc. Natl Acad. Sci. USA 114(4), E570-E579 (2017).

127 Actor JK, Shirai M, Kullberg MC, Buller RM, Sher A, Berzofsky JA. Helminth infection results in decreased virus-specific CD8+ cytotoxic T-cell and Th1 cytokine responses as well as delayed virus clearance. Proc. Natl Acad. Sci. USA 90(3), 948-952 (1993).

128 Cooper PJ, Chico M, Sandoval C et al. Human infection with Ascaris lumbricoides is associated with suppression of the interleukin-2 response to recombinant cholera toxin B subunit following vaccination with the live oral Cholera vaccine CVD 103-HgR. Infect. Immun. 69(3), 1574-1580 (2001).

129 Netea MG, Joosten LA, Latz E et al. Trained immunity: a program of innate immune memory in health and disease. Science 352(6284), aaf1098 (2016).

130 Parker EP, Kampmann B, Kang G, Grassly NC. Influence of enteric infections on response to oral poliovirus vaccine: a systematic review and meta-analysis. J. Infect. Dis. 210(6), 853-864 (2014).

131 Taniuchi M, Platts-Mills JA, Begum S et al. Impact of enterovirus and other enteric pathogens on oral polio and rotavirus vaccine performance in Bangladeshi infants. Vaccine 34(27), 3068-3075 (2016).

132 Wang H, Moon S, Wang Y, Jiang B. Multiple virus infection alters rotavirus replication and expression of cytokines and Toll-like receptors in intestinal epithelial cells. Virus Res. 167(1), 48-55 (2012).

133 Zaman K, Sack DA, Yunus M et al. Successful co-administration of a human rotavirus and oral poliovirus vaccines in Bangladeshi infants in a 2-dose schedule at 12 and 16 weeks of age. Vaccine 27(9), 1333-1339 (2009).

134 Patel M, Steele AD, Parashar UD. Influence of oral polio vaccines on performance of the monovalent and pentavalent rotavirus vaccines. Vaccine 30(Suppl. 1), A30-A35 (2012).

135 Emperador DM, Velasquez DE, Estivariz CF et al. Interference of monovalent, bivalent, and trivalent oral poliovirus vaccines on monovalent rotavirus vaccine immunogenicity in rural Bangladesh. Clin. Infect. Dis. 62(2), 150-156 (2016).

136 Cardemil CV, Estivariz C, Shrestha L et al. The effect of diarrheal disease on bivalent oral polio vaccine (bOPV) immune response in infants in Nepal. Vaccine 34(22), 2519-2526 (2016).

137 Maldonado YA, Pena-Cruz V, De La Luz Sanchez M et al. Host and viral factors affecting the decreased immunogenicity of Sabin type 3 vaccine after administration of trivalent oral polio vaccine to rural Mayan children. J. Infect. Dis. 175(3), 545-553 (1997).

138 Triki H, Abdallah MV, Ben Aissa R et al. Influence of host related factors on the antibody response to trivalent oral polio vaccine in Tunisian infants. Vaccine 15(10), 1123-1129 (1997).

139 Kotloff KL, Wasserman SS, O’Donnell S, Losonsky GA, Cryz SJ, Levine MM. Safety and immunogenicity in North Americans of a single dose of live oral cholera vaccine CVD 103-HgR: results of a randomized, placebo-controlled, double-blind crossover trial. Infect. Immun. 60(10), 4430-4432 (1992).

140 Qadri F, Bhuiyan TR, Sack DA, Svennerholm AM. Immune responses and protection in children in developing countries induced by oral vaccines. Vaccine 31(3), 452-460 (2013).

141 Bruckner S, Agnandji ST, Elias J et al. A single-dose antihelminthic treatment does not influence immunogenicity of a meningococcal and a cholera vaccine in Gabonese school children. Vaccine 34(44), 5384-5390 (2016).

142 Clark CE, Fay MP, Chico ME et al. Maternal helminth infection is associated with higher infant immunoglobulin A titers to antigen in orally administered vaccines. J. Infect. Dis. 213(12), 1996-2004 (2016).

143 Dominguez-Bello MG, Costello EK, Contreras M et al. Delivery mode shapes the acquisition and structure of the initial microbiota across multiple body habitats in newborns. Proc. Natl Acad. Sci. USA 107(26), 11971-11975 (2010). 
144 Smith K, McCoy KD, Macpherson AJ. Use of axenic animals in studying the adaptation of mammals to their commensal intestinal microbiota. Semin. Immunol. 19(2), 59-69 (2007).

145 Ivanov Ii, Atarashi K, Manel N et al. Induction of intestinal Th17 cells by segmented filamentous bacteria. Cell 139(3), 485-498 (2009).

146 Pfeiffer JK, Virgin HW. Viral immunity. Transkingdom control of viral infection and immunity in the mammalian intestine. Science 351(6270), (2016).

147 Kuss SK, Best GT, Etheredge CA et al. Intestinal microbiota promote enteric virus replication and systemic pathogenesis. Science 334(6053), 249-252 (2011).

-. Demonstrates the importance of the bacterial microbiota for poliovirus infectivity.

148 Robinson CM, Jesudhasan PR, Pfeiffer JK. Bacterial lipopolysaccharide binding enhances virion stability and promotes environmental fitness of an enteric virus. Cell. Host Microbe 15(1), 36-46 (2014).

149 Uchiyama R, Chassaing B, Zhang B, Gewirtz AT. Antibiotic treatment suppresses rotavirus infection and enhances specific humoral immunity. J. Infect. Dis. 210(2), 171-182 (2014).

150 De Filippo C, Cavalieri D, Di Paola M et al. Impact of diet in shaping gut microbiota revealed by a comparative study in children from Europe and rural Africa. Proc. Natl Acad. Sci. USA 107(33), 14691-14696 (2010).

151 Yatsunenko T, Rey FE, Manary MJ et al. Human gut microbiome viewed across age and geography. Nature 486(7402), 222-227 (2012).

152 Nakayama J, Watanabe K, Jiang J et al. Diversity in gut bacterial community of school-age children in Asia. Sci. Rep. 5, 8397 (2015).

153 Pehrsson EC, Tsukayama P, Patel S et al. Interconnected microbiomes and resistomes in low-income human habitats. Nature 533(7602), 212-216 (2016).

154 Davenport ER, Mizrahi-Man O, Michelini K, Barreiro LB, Ober C, Gilad Y. Seasonal variation in human gut microbiome composition. PLoS ONE 9(3), e90731 (2014).

155 Huda MN, Lewis Z, Kalanetra KM et al. Stool microbiota and vaccine responses of infants. Pediatrics 134(2), e362-e372 (2014).

156 Harris VC, Armah G, Fuentes S et al. Significant correlation between the infant gut microbiome and rotavirus vaccine response in rural Ghana. J. Infect. Dis. 215(1), 34 (2016).

157 Parker E. Influence of the intestinal microbiota on the immune response to oral poliovirus and rotavirus vaccines in a low-income community in South India (2016). https://spiral.imperial.ac.uk/handle/10044/1/42504

158 Praharaj I, John SM, Bandyopadhyay R, Kang G. Probiotics, antibiotics and the immune responses to vaccines. Philos. Trans. R Soc. Lond. B Biol. Sci. 370(1671), pii:20140144 (2015).

159 Smith MI, Yatsunenko T, Manary MJ et al. Gut microbiomes of Malawian twin pairs discordant for kwashiorkor. Science 339(6119), 548-554 (2013).

160 Nagao-Kitamoto H, Shreiner AB, Gillilland MG et al. Functional characterization of inflammatory bowel disease-associated gut dysbiosis in gnotobiotic mice. Cell. Mol. Gastroenterol. Hepatol. 2, 468-481 (2016).

161 Twitchell EL, Tin C, Wen K et al. Modeling human enteric dysbiosis and rotavirus immunity in gnotobiotic pigs. Gut Pathog. 8, 51 (2016).

162 Korpe PS, Petri WA Jr. Environmental enteropathy: critical implications of a poorly understood condition. Trends Mol. Med. 18(6), 328-336 (2012).

163 Prendergast A, Kelly P. Enteropathies in the developing world: neglected effects on global health. Am. J. Trop. Med. Hyg. 86(5), 756-763 (2012).

164 Chacko CJ, Paulson KA, Mathan VI, Baker SJ. The villus architecture of the small intestine in the tropics: a necropsy study. J. Pathol. 98(2), 146-151 (1969).

165 Brown EM, Wlodarska M, Willing BP et al. Diet and specific microbial exposure trigger features of environmental enteropathy in a novel murine model. Nat. Commun. 6, 7806 (2015).

166 Serazin AC, Shackelton LA, Wilson C, Bhan MK. Improving the performance of enteric vaccines in the developing world. Nat. Immunol. 11(9), 769-773 (2010).

167 Keusch GT, Denno DM, Black RE et al. Environmental enteric dysfunction: pathogenesis, diagnosis, and clinical consequences. Clin. Infect. Dis. 59(Suppl. 4), S207-S212 (2014).

168 Levine MM. Immunogenicity and efficacy of oral vaccines in developing countries: lessons from a live cholera vaccine. BMC Biol. 8, 129 (2010).

169 Kelly P, Menzies I, Crane R et al. Responses of small intestinal architecture and function over time to environmental factors in a tropical population. Am. J. Trop. Med. Hyg. 70(4), 412-419 (2004).

170 Lagos R, Fasano A, Wasserman SS et al. Effect of small bowel bacterial overgrowth on the immunogenicity of single-dose live oral cholera vaccine CVD 103-HgR. J. Infect. Dis. 180(5), 1709-1712 (1999).

171 Naylor C, Lu M, Haque R et al. Environmental enteropathy, oral vaccine failure and growth faltering in infants in Bangladesh. EBioMedicine 2(11), 1759-1766 (2015). 
172 Kosek MN, Mduma E, Kosek PS et al. Plasma tryptophan and the kynurenine-tryptophan ratio are associated with the acquisition of statural growth deficits and oral vaccine underperformance in populations with environmental enteropathy. Am. J. Trop. Med. Hyg. 95(4), 928-937 (2016).

173 Becker-Dreps S, Vilchez S, Bucardo F et al. The association between fecal biomarkers of environmental enteropathy and rotavirus vaccine response in Nicaraguan infants. Pediatr. Infect. Dis. J. 36(4), 412-416 (2017).

174 Cunliffe N, Zaman K, Rodrigo C et al. Early exposure of infants to natural rotavirus infection: a review of studies with human rotavirus vaccine RIX4414. BMC Pediatr. 14, 295 (2014).

175 Kompithra RZ, Paul A, Manoharan D et al. Immunogenicity of a three dose and five dose oral human rotavirus vaccine (RIX4414) schedule in south Indian infants. Vaccine 32(Suppl. 1), A129-A133 (2014).

176 Su-Arehawaratana P, Singharaj P, Taylor DN et al. Safety and immunogenicity of different immunization regimens of CVD 103-HgR live oral cholera vaccine in soldiers and civilians in Thailand. J. Infect. Dis. 165(6), 1042-1048 (1992).

177 Anh DD, Canh DG, Lopez AL et al. Safety and immunogenicity of a reformulated Vietnamese bivalent killed, whole-cell, oral cholera vaccine in adults. Vaccine 25(6), 1149-1155 (2007).

178 Mahalanabis D, Lopez AL, Sur D et al. A randomized, placebo-controlled trial of the bivalent killed, whole-cell, oral cholera vaccine in adults and children in a cholera endemic area in Kolkata, India. PLoS ONE 3(6), e2323 (2008).

179 Steele AD, Neuzil KM, Cunliffe NA et al. Human rotavirus vaccine Rotarix provides protection against diverse circulating rotavirus strains in African infants: a randomized controlled trial. BMC Infect. Dis. 12, 213 (2012).

180 Bhandari N, Rongsen-Chandola T, Bavdekar A et al. Efficacy of a monovalent human-bovine (116E) rotavirus vaccine in Indian children in the second year of life. Vaccine 32(Suppl. 1), A110-A116 (2014).

181 Braeckman T, Van Herck K, Meyer N et al. Effectiveness of rotavirus vaccination in prevention of hospital admissions for rotavirus gastroenteritis among young children in Belgium: case-control study. BMJ 345, e4752 (2012).

182 Bar-Zeev N, Jere KC, Bennett A et al. Population impact and effectiveness of monovalent rotavirus vaccination in urban Malawian children 3 years after vaccine introduction: ecological and case-control analyses. Clin. Infect. Dis. 62(Suppl. 2), S213-S219 (2016).

183 Ramachandran M, Das BK, Vij A et al. Unusual diversity of human rotavirus G and P genotypes in India. J. Clin. Microbiol. 34(2), 436-439 (1996).

184 Gentsch JR, Laird AR, Bielfelt B et al. Serotype diversity and reassortment between human and animal rotavirus strains: implications for rotavirus vaccine programs. J. Infect. Dis. 192(Suppl. 1), S146-S159 (2005).

185 Simanjuntak CH, Paleologo FP, Punjabi NH et al. Oral immunisation against typhoid fever in Indonesia with Ty21a vaccine. Lancet 338(8774), 1055-1059 (1991).

186 Schoub BD, Johnson S, McAnerney JM et al. Poliomyelitis outbreak in Natal/KwaZulu, South Africa, 1987-1988. 2. Immunity aspects. Trans. R Soc. Trop. Med. Hyg. 86(1), 83-85 (1992).

187 Henry JL, Jaikaran ES, Davies JR et al. A study of poliovaccination in infancy: excretion following challenge with live virus by children given killed or living poliovaccine. J. Hyg. (Lond) 64(1), 105-120 (1966).

188 Onorato IM, Modlin JF, McBean AM, Thoms ML, Losonsky GA, Bernier RH. Mucosal immunity induced by enhance-potency inactivated and oral polio vaccines. J. Infect. Dis. 163(1), 1-6 (1991).

189 Enane LA, Gastanaduy PA, Goldfarb DM et al. Impact of rotavirus vaccination on hospitalizations and deaths from childhood gastroenteritis in Botswana. Clin. Infect. Dis. 62(Suppl. 2), S168-S174 (2016).

190 Mpabalwani EM, Simwaka CJ, Mwenda JM et al. Impact of rotavirus vaccination on diarrheal hospitalizations in children aged $<5$ years in Lusaka, Zambia. Clin. Infect. Dis. 62(Suppl. 2), S183-S187 (2016).

191 Church J, Parker E, Kirkpatrick B, Grassly N, Prendergast A. Interventions to improve oral vaccine performance in developing countries: systematic review and meta-analysis (2017). www.crd.york.ac.uk/PROSPERO/display_record.asp?ID=CRD42017060608

192 Clarke E, Desselberger U. Correlates of protection against human rotavirus disease and the factors influencing protection in low-income settings. Mucosal Immunol. 8(1), 1-17 (2015).

193 GPEI. Polio eradication and endgame strategic plan (2013-2018). (2013).

194 John TJ. Antibody response of infants in tropics to five doses of oral polio vaccine. Br. Med. J. 1(6013), 812 (1976).

195 McBean AM, Thoms ML, Albrecht P, Cuthie JC, Bernier R. Serologic response to oral polio vaccine and enhanced-potency inactivated polio vaccines. Am. J. Epidemiol. 128(3), 615-628 (1988).

196 Perez-Schael I, Salinas B, Tomat M et al. Efficacy of the human rotavirus vaccine RIX4414 in malnourished children. J. Infect. Dis. 196(4), 537-540 (2007).

197 Deforest A, Parker PB, Diliberti JH, Yates HT Jr, Sibinga MS, Smith DS. The effect of breast-feeding on the antibody response of infants to trivalent oral poliovirus vaccine. J. Pediatr. 83(1), 93-95 (1973).

198 Ho MS, Floyd RL, Glass RI et al. Simultaneous administration of rhesus rotavirus vaccine and oral poliovirus vaccine: immunogenicity and reactogenicity. Pediatr. Infect. Dis. J. 8(10), 692-696 (1989). 
199 Kollaritsch H, Que JU, Kunz C, Wiedermann G, Herzog C, Cryz SJ Jr. Safety and immunogenicity of live oral cholera and typhoid vaccines administered alone or in combination with antimalarial drugs, oral polio vaccine, or yellow fever vaccine. J. Infect. Dis. 175(4), 871-875 (1997).

200 WHO. Rotavirus vaccines. Wkly Epidemiol. Rec. 82, 285-295 (2007).

201 Tregnaghi MW, Abate HJ, Valencia A et al. Human rotavirus vaccine is highly efficacious when coadministered with routine expanded program of immunization vaccines including oral poliovirus vaccine in Latin America. Pediatr. Infect. Dis. J. 30(6), e103-e108 (2011).

202 John TJ, Christopher S. Oral polio vaccination of children in the tropics. III. Intercurrent enterovirus infections, vaccine virus take and antibody response. Am. J. Epidemiol. 102(5), 422-428 (1975).

203 Ruiz-Palacios GM, Perez-Schael I, Velazquez FR et al. Safety and efficacy of an attenuated vaccine against severe rotavirus gastroenteritis. N. Engl. J. Med. 354(1), 11-22 (2006).

204 Phua KB, Lim FS, Lau YL et al. Safety and efficacy of human rotavirus vaccine during the first 2 years of life in Asian infants: randomised, double-blind, controlled study. Vaccine 27(43), 5936-5941 (2009). 